OPEN ACCESS

Edited by:

Farnaz Ghorbani,

Fudan University, China

Reviewed by:

Amir Seyedsalehi,

University of Connecticut,

United States

Ebrahim Tavakoli,

Materials and Energy Research

Center, Iran

Farnoosh Saeedinejad,

University of Connecticut,

United States

*Correspondence:

Quanyi Guo

doctorguo_301@163.com

Zhiwei Chen

czw9915@sina.com

${ }^{t}$ These authors share first authorship

Specialty section:

This article was submitted to Biomaterials,

a section of the journal

Frontiers in Bioengineering and

Biotechnology

Received: 05 February 2021

Accepted: 14 April 2021

Published: 04 May 2021

Citation:

Wei F, Liu S, Chen M, Tian G, Zha $K$, Yang Z, Jiang S, Li M, Sui $X$,

Chen Z and Guo Q (2021) Host

Response to Biomaterials

for Cartilage Tissue Engineering: Key

to Remodeling.

Front. Bioeng. Biotechnol. 9:664592.

doi: 10.3389/fbioe.2021.664592

\section{Host Response to Biomaterials for Cartilage Tissue Engineering: Key to Remodeling}

\author{
Fu Wei ${ }^{1,2+}$, Shuyun Liu', Mingxue Chen ${ }^{3}$, Guangzhao Tian 1,4, Kangkang Zha',4, \\ Zhen Yang ${ }^{1,4}$, Shuangpeng Jiang ${ }^{5}$, Muzhe Li ${ }^{2}$, Xiang Sui ${ }^{1}$, Zhiwei Chen ${ }^{2 *}$ and \\ Quanyi Guo ${ }^{1 *}$
}

\begin{abstract}
${ }^{1}$ Beijing Key Lab of Regenerative Medicine in Orthopedics, Key Laboratory of Musculoskeletal Trauma and War Injuries, PLA, Institute of Orthopedics, Chinese PLA General Hospital, Beijing, China, ${ }^{2}$ Department of Orthopedics, The First Affiliated Hospital of University of South China, Hengyang, China, ${ }^{3}$ Department of Orthopedic Surgery, Beijing Jishuitan Hospital, Fourth Clinical College of Peking University, Beijing, China, ${ }^{4}$ School of Medicine, Nankai University, Tianjin, China, ${ }^{5}$ The First Hospital of China Medical University, Shenyang, China
\end{abstract}

Biomaterials play a core role in cartilage repair and regeneration. The success or failure of an implanted biomaterial is largely dependent on host response following implantation. Host response has been considered to be influenced by numerous factors, such as immune components of materials, cytokines and inflammatory agents induced by implants. Both synthetic and native materials involve immune components, which are also termed as immunogenicity. Generally, the innate and adaptive immune system will be activated and various cytokines and inflammatory agents will be consequently released after biomaterials implantation, and further triggers host response to biomaterials. This will guide the constructive remolding process of damaged tissue. Therefore, biomaterial immunogenicity should be given more attention. Further understanding the specific biological mechanisms of host response to biomaterials and the effects of the host-biomaterial interaction may be beneficial to promote cartilage repair and regeneration. In this review, we summarized the characteristics of the host response to implants and the immunomodulatory properties of varied biomaterial. We hope this review will provide scientists with inspiration in cartilage regeneration by controlling immune components of biomaterials and modulating the immune system.

Keywords: biomaterials, immunomodulation, macrophage, tissue engineering, cartilage

\section{INTRODUCTION}

Articular cartilage lacks blood vessels, nerves and lymphatic vessels, has a smooth surface and is translucent. It is a form of hyaline cartilage, which is a highly organized connective tissue (Sophia-Fox et al., 2009). Articular cartilage bears mechanical loads and provides cushioning and lubrication, and its protective function is weakened after injury. Due to the lack of self-healing capacity of cartilage, joint injury and progressive degeneration, osteoarthritis (OA) eventually develops, and it becomes difficult to avoid joint arthroplasty (Widuchowski et al., 2007). Therefore, the early repair of damaged articular cartilage is necessary. 
Non-operative treatment often involves oral glucosamine sulfate to nourish cartilage and intra-articular injections of Hyaluronic acid (HA) to lubricate the joint. Traditional surgical treatment includes abrasion, subchondral drilling, microfracture, osteochondral autograft transfer system (OATS) (also known as mosaicplasty), and autologous chondrocyte implantation (ACI) (Pestka et al., 2012; Albright and Daoud, 2017; Solheim et al., 2018). However, these methods have achieved limited success. HA offers little protection against early cartilage damage (Nathani et al., 2019). Microfracture is used to treat small articular cartilage lesions that form fibrocartilage and are therefore mechanically weak and prone to degeneration (Benthien and Behrens, 2013). Mosaicplasty is usually suitable for the damage involving subchondral bone, but donor area complications and dead spaces between cylindrical grafts may increase the chance of repair failure (Kock et al., 2008). ACI is a cell-engineering base surgical procedure, but the quality of restoration is severely compromised by the loss of therapeutic chondrocytes (McCarthy et al., 2016). There is an urgent clinical need for new strategies to induce cartilage regeneration. Tissue engineering has emerged in recent years as a promising approach to repair injured cartilage (Makris et al., 2015), aiming to exploit the inherent regenerative potential of human tissues and organs in the degraded state and restore or reconstruct the normal function of the body.

As an indispensable element of the tissue engineering triad, biomaterials not only provide mechanical support for cells, but also act as carriers for bioactive molecules (e.g., growth factors). The biomaterials used to fabricate scaffolds can be roughly divided into two main categories: synthetic polymers, including polycaprolactone (PCL), poly(lactic acid) (PLA), poly(glycolic acid) (PGA), poly(lactic-co-glycolic acid) (PLGA), and poly(L-lactic acid) (PLLA), among others. Alternatively, naturally derived biomaterials are for instance decellularized extracellular matrix (dECM) from diverse tissues and natural molecules such as collagen, gelatin, silk fibroin, HA, alginate, and chitosan, et al. These materials can be used to fabricate different geometric shapes by $3 \mathrm{D}$ printing, electrospinning, injection molding techniques and among others (Chen et al., 2018; Lukanina et al., 2018; Xia et al., 2018; Lu et al., 2019). The scaffolds fabricated using these two kinds of biomaterials have advantages and disadvantages (Londono and Badylak, 2015). Compared with synthetic polymers, naturally derived biomaterials have a composition closer to that of cartilage, good biocompatibility and low cytotoxicity, and they are beneficial for cell adhesion, proliferation and differentiation (Huang et al., 2019; Xiao et al., 2019). However, these materials are limited in terms of processability and manipulatable degradation time (Pati et al., 2014). In contrast, synthetic polymers have good mechanical strength, controllable degradation and high plasticity (Li et al., 2019b; Stefani et al., 2020). But they also have shortcomings, such as poor biocompatibility, acidic degradation products, low biological activity, hydrophobicity and limited interfacial integration with tissue (Stocco et al., 2014; Park et al., 2018; Lin et al., 2019).

The great potential of tissue engineering for cartilage repair has given rise to new hope. As mentioned above, a wide variety of biomaterials have been researched and developed to achieve better repair and regeneration outcomes. But up to now, when implanted into vivo, most of the biomaterials have not worked as expected, some even lead to acute or chronic inflammation (Cipriano et al., 2017; Vollkommer et al., 2019). An important link seems to have been ignored by us. Numerous researches on cartilage tissue engineering are focused on the effect of biomaterial's physical properties and physicochemical properties on repair outcome. However, limited studies have focused on how biomaterials affect host response, such as inflammation and immune modulation. Studies have suggested that implanted biomaterial induced adverse immune response is associated with a prolonged reaction time, delayed interface connection and integration, and reconstruction failure (Sirlin et al., 2001; Fraitzl et al., 2008). It has also been shown that the host immune response has a positive effect on the reparative effect of tissue engineering scaffolds to some extent (Sadtler et al., 2019). Direct use of acellular extracellular matrix (ECM) or native ECM components can elicit a favorable immune response prior to tissue remodeling outcome. This immunomodulation usually depends on the composition and structure of the scaffold. Tissue-derived ECM scaffolds induce a pro-regeneration immune environment through Th2 immune response, which drive macrophage polarization toward M2 phenotype via IL-4 (Cipriano et al., 2017). Besides, the regulatory role of pore size and porosity of scaffold in host response has also been confirmed (Orenstein et al., 2010; Junge et al., 2012). In scaffold strategy based on loading immunomodulatory function cells, mesenchymal stem cells (MSCs), as commonly used seed cells, can regulate local immune response by secreting anti-inflammatory and proinflammatory cytokines to promote repair (English, 2013; Nagubothu et al., 2020). Indeed, the interaction between implanted biomaterial and host immune system is crucial in determining the constructive and functional outcome. Host response is considered to be influenced by the immune components (also known as immunogenicity) of biomaterial, cytokines, or inflammatory agents induced by implants and injured tissue. As such the immunogenicity of implanted biomaterials should not be ignored. Additionally, cartilage is believed to be a tissue with "immune privilege," located in a relatively closed environment (Smith et al., 2015). Nevertheless, cartilage tissue injury is accompanied by the disruption of balanced environment, release of inflammatory cytokines and chemokines, and immune/inflammatory cells migration will further promote the response of the host immune system to the implanted biomaterial.

The host response to biomaterials plays a central role in tissue repair and regeneration, have both positive and negative implication for the healing process. An effective biomaterial-based immune modulation strategy is becoming an attractive approach in the field of regenerative medicine (Hachim et al., 2019; Shahbaz et al., 2020; Wu et al., 2020). This review summarizes the characteristics of the interaction between host immune system and implanted biomaterial, and the immunomodulatory properties of common biomaterials in the hope of providing inspiration for next generation of tissue engineering regeneration strategy. 


\section{HOST RESPONSE FOLLOWING BIOMATERIAL IMPLANTATION}

Biomaterials implanted into damaged tissues come into contact with cells, surrounding tissues and blood and thus cannot avoid activating the immune system by triggering a foreign body reaction. In fact, the relationship between biomaterialmediated tissue healing and immune response is very complex, with many cell types, plasma proteins, and extracellular fluid components being involved. The reaction of the biomaterial with the surrounding environment is actually an important factor in determining its biocompatibility. The host response (including immune, inflammatory and foreign body reactions, etc.) can be local or systemic, which is mainly influenced by immune components of the implant, type of biomaterial or injured tissue, and biomaterial surface chemistry and degradation characteristics, and so on. This will ultimately affect the lifespan of the implant and the outcome of the repair.

\section{The Vroman Effect of Implanted Biomaterials}

Biomaterial-mediated host reactions are primarily caused by host cell recognition of the biomaterial surface, which is based on the adsorption of adhesion proteins to the surface of the biomaterial. Adhesion proteins, such as fibrinogen, vitronectin, fibronectin, albumin, $\gamma$ globulin, complement, and others, form a protein layer on the surface of the biomaterial to modulate host inflammatory cell interactions and adhesion (Pape et al., 2017; Tanaka et al., 2017; Horbett, 2018). The process of cell adsorption to and spreading on the biomaterial surface is mediated by adhesion proteins. The effect of a biomaterial on the cell or host reaction is actually achieved by influencing the adhesion behavior of proteins to the surface. The type, concentration and spatial conformation of the adhesion protein will directly activate the response of the host immune cell to the biomaterial (Wilson et al., 2005), i.e., resulting in an innate or adaptive immune response. In turn, the type, concentration and spatial conformation of these adsorbed proteins depend on the surface characteristics of the biomaterial, which determine the adsorption, survival and function of cells (especially monocytes and macrophages) in the protein layer (Anderson et al., 2008). Protein adhesion is a dynamic process, a high concentration of adhesion proteins first arrive and adsorb onto the surface of the implant, and these proteins will eventually be replaced by proteins with a high affinity for the surface of the biomaterial. The phenomenon of protein adsorption and desorption is known as the Vroman effect (Figure 1; Hirsh et al., 2013; Kim, 2017). After implantation, biomaterial is immediately covered by proteins in the blood and tissue fluid, which direct the subsequent cascade biological reactions. Studies have shown that the orientation and conformation of fibrinogen on the surface of biomaterials can modulate neutrophils adhesion (Milleret et al., 2015). There is a direct relationship between a stronger adhesion capacity on the surface of biomaterials and more desirable cell adhesion and growth (Shamloo and Sarmadi, 2016). It is well known that at similar surface roughness, hydrophilic surfaces preferentially adsorb proteins and promote cell adhesion and growth compared to hydrophobic surfaces (Chaudhary et al., 2012). By immobilizing proteins on the biomaterial surface, developing a biointerface that can enhance cell "homing" ability is one of the critical factors in biomaterial development (Chrzanowski et al., 2012). The biomaterial surface properties, protein adsorption and cellular responses are considered to be interrelated and ultimately determine the biocompatibility of the biomaterial (Allen et al., 2006). The relationship between these different but related phenomena remains to be elucidated.

\section{The Main Actors in Host-Biomaterial Interaction}

There is a class of integrin receptors on the cell surface that can specifically recognize certain peptides of adhesion proteins, thereby affecting cell adhesion, migration, activity, and other functions (Yang et al., 2013). The type and level of cell adhesion proteins change in a time-dependent manner (Xu and Siedlecki, 2007). The early stage of host response following tissue injury is characterized by a predominance of neutrophils, which are the first inflammatory cell type to arrive at the site of injury. Neutrophils are capable of phagocytosis and degradation of foreign substances, dead cells, and providing signaling molecules to recruit macrophages to injury site. Mast cells modulate the inflammatory response by releasing particles, such as histamine, IL-4, and IL-13 that can recruit macrophages and facilitate their fusion into foreign body giant cells (DeFife et al., 1997; Ang et al., 1998; McNally and Anderson, 2002). Macrophages begin to infiltrate approximately $12 \mathrm{~h}$ post-injury, but their response lasts longer than that of neutrophils, and subsequently become the dominant cell type within the site of injury. The role of macrophages in tissue repair and regeneration is very complex, could perform beneficial or detrimental functions. That is, deciding toward to a constructive and functional outcome or scar tissue formation. The T lymphocyte cell population plays an important regulatory role in tissue repair by the secretion of cytokines and chemokines, many of which are considered to influence macrophage polarization. Moreover, dendritic cells, natural killer (NK) cells, B lymphocytes, plasmocytes, and among others also participate in the immune response to varying degrees (Figure 1). The occurrence and outcome of a series of events will vary according to the surface chemistry, stiffness, and degradation properties of biomaterials, as well as other factors that have not been elucidated (Brodbeck et al., 2001).

With the advances in tissue engineering and regeneration medicine, it has now become clear that the immune system plays a critical role in tissue repair process (Julier et al., 2017). Repair strategy of immune system regulated through biomaterials is aim at activating desired components of inflammatory, proliferation, and remolding phase to promote a constructive and functional remolding outcome. Allowing specific biological response is beneficial to both the integration and performance, the current challenge is the development of biomaterials or delivery systems capable of modulating the immune system as a way of stimulating tissue repair and regeneration (Badylak et al., 2008). Therefore, a deeper understanding of immunological profile of biomaterials 


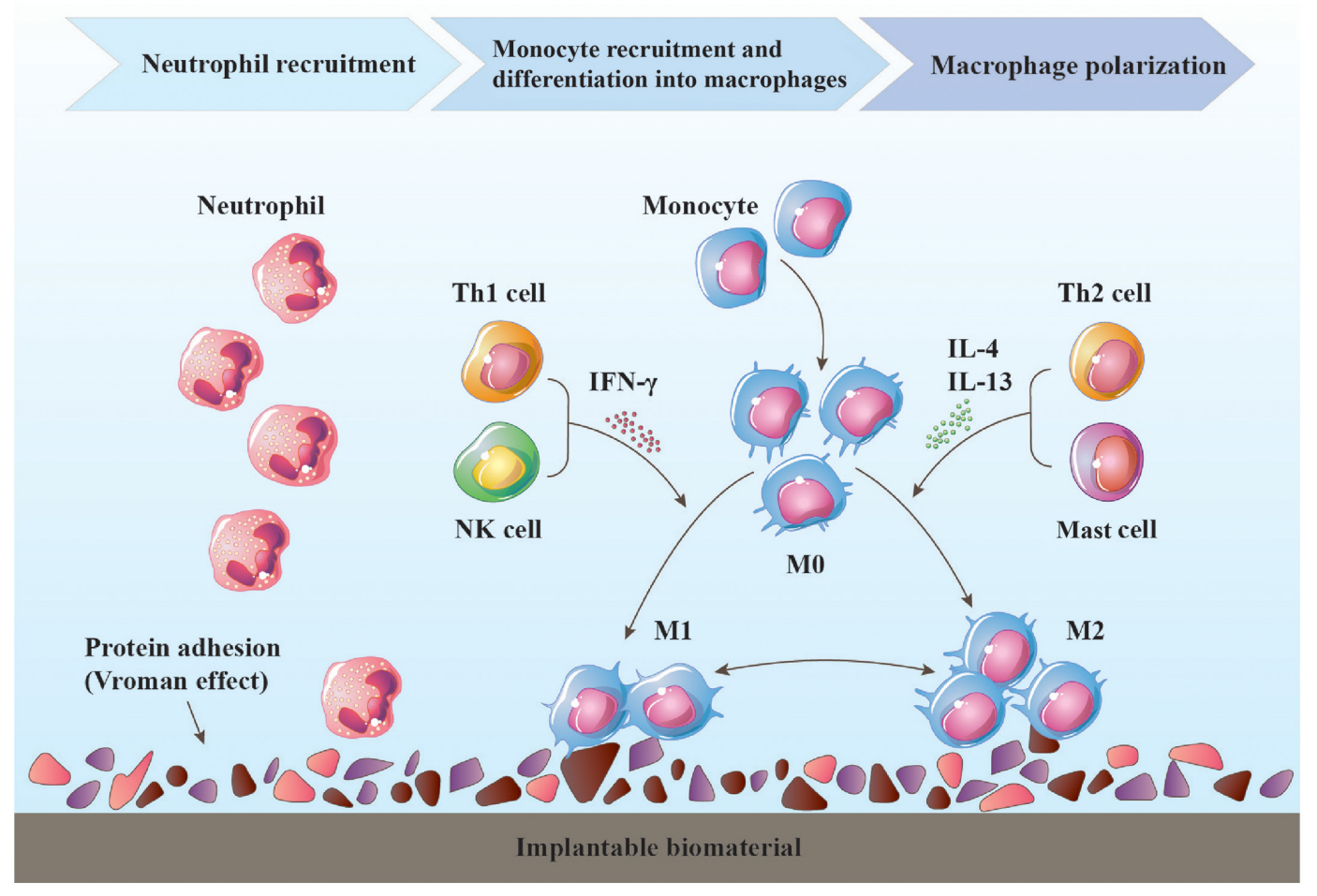

FIGURE 1 | Immune response to an implantable biomaterial. Various proteins adhere to the surface of the biomaterial. Neutrophils are first recruited, followed by monocyte-derived macrophages, which become the dominant cell type around the biomaterial. Macrophage differentiation is temporary, and the polarization state may change depending on the tissue milieu. The timely transition of the macrophage phenotype from proinflammatory M1 to anti-inflammatory and

immunomodulatory M2 is critical for constructive tissue remodeling, and other immune cells (T helper cells, NK cells, mast cells, etc.) are also involved in this process.

and the interaction of immune system and biomaterials interaction is essential for the better repair outcomes.

\section{IMMUNOLOGICAL CHARACTERIZATION OF BIOMATERIALS}

\section{Synthetic Polymers}

In the body, articular cartilage is subjected to multiaxial loads, including those resulting from compression, tension, shear and fluid flow (Pattappa et al., 2019). Articular cartilage exhibits excellent biomechanics due to its unique hyalinelike cartilage composition and the ultrastructure of the ECM, especially the tight network of type II collagen (Col II) fibrils and abundant negatively charged proteoglycan chains. The controlled mechanical properties of synthetic polymers can meet the biomechanical requirements of the process of cartilage regeneration (Silva et al., 2020). Synthetic polymers have good plasticity, and their microstructure, morphology, and degradation rate can be predesigned and regulated according to the biology of specific tissue (Wang et al., 2020b). PCL (Venugopal et al., 2019), PLA (Baena et al., 2019), PGA (Lin et al., 2017), and PLGA (Kim et al., 2019) are the most representative and widely used synthetic polymers, and have been approved by the FDA for clinical human use. Scaffolds made from synthetic polymers temporarily provide mechanical support after implantation, as well as a microenvironment for cell growth, proliferation and differentiation, thereby regulating and inducing tissue differentiation and regeneration (Li S. et al., 2020; Salonius et al., 2020). The structure of the scaffold is very important for cartilage regeneration, and tissue engineering applications often require the use of porous three-dimensional (3D) scaffolds to facilitate cell migration and cell-cell interactions (Schipani et al., 2020). Secondly, during the process of regeneration, scaffold should also have sufficient strength to resist the physiological load, and the stress should be properly distributed to the surrounding tissue (Lohfeld et al., 2015). The good printing properties of synthetic polymers allow their combination with 3D printing techniques to effectively address this issue. The controllability, reproducibility and good mechanical properties of synthetic polymers show promising applications in cartilage tissue engineering. However, the lower bioactivity they exhibit is not favorable for incorporating with host tissues, as they may lead to increased local $\mathrm{pH}$ through acidic degradation products, immune response or toxicity, and inflammation associated with high molecular weight polymers.

\section{Acidic Degradation Products of Synthetic Polymers}

Synthetic polymers have one common feature: degradability. Degradation occurs progressively (by chemical hydrolysis or enzymatic degradation) over time after implantation. Acidic 
degradation products reduce the $\mathrm{pH}$ of the surrounding environment, leading to inflammatory cell infiltration and aseptic inflammation (Lendlein and Langer, 2002). Clinical reports have shown that up to approximately $8 \%$ of patients treated with PGA had non-infectious inflammation (Peppas and Langer, 1994). The longer the biodegradation cycle of synthetic polymers, the greater the probability of inducing an adverse host response, this event is related to the acidic degradation products and immunogenicity of the polymer. Acidic products (e.g., lactic acid, glycolic acid) will trigger an autocatalytic reaction when reducing the $\mathrm{pH}$, which can accelerate the formation of the products (Göpferich, 1996; Burkersroda et al., 2002; Eglin and Alini, 2008). When the accumulation of acidic products exceeds the metabolic capacity of the body, the gradually decreasing acidity of the environment in turn accelerates the degradation of the biomaterial. These acidic products are one of the factors involved in the hostbiomaterial reaction (Rezwan et al., 2006). In addition, the surface chemistry, structure, type, purity, and crystallinity of the biomaterials also influence the occurrence, extent and outcome of the host-biomaterial interaction (Milleret et al., 2015; Jiang et al., 2016; Stratton et al., 2016).

\section{Surface Chemistry: Hydrophobicity/Hydrophilicity, Chemical Groups, Charge Characteristics}

As previously mentioned, the adsorption of proteins on biomaterial surface is essential for the cell-biomaterial interaction (Ekdahl et al., 2012). A factor that directly determines the type, amount and conformation of adhesion proteins is the biomaterial surface chemistry, such as its hydrophobicity/hydrophilicity, chemical moieties and charge characteristics. By changing the biomaterial surface chemistry to regulate the adsorption of proteins, it has been shown that hydrophilic and anionic chemistries are more likely to induce macrophage apoptosis than hydrophobic or cationic surfaces, which may result in no inflammatory outcome (Brodbeck et al., 2001). Macrophages play an important and complex role in the regulation of the immune microenvironment of implant, moreover, the adhesion and activation of lymphocytes also depend on macrophages. Macrophage plasticity allows their adaptation to different stimuli (Rostam et al., 2016). M1 macrophages can drive the inflammatory response, causing the scaffold to be wrapped in fibrous tissue, separating it from the surrounding tissue (Fujihara et al., 2020). In contrast, M2 macrophages have antiinflammatory properties and promote repair (Ma et al., 2014; Hotchkiss et al., 2018; Deng et al., 2020).

The commonly used synthetic polymers are hydrophobic, with a surface that has a high affinity for many kinds of proteins. When protein molecules adsorb onto the surface of a hydrophobic biomaterial, their conformation changes through hydrophobic interactions, exposing the hydrophobic domain and facilitating close binding to the surface (Lu and Park, 1991; Hu et al., 2001; Collier and Anderson, 2002; Heuberger et al., 2005; Evans-Nguyen et al., 2006). There is a direct correlation between the hydrophobicity of biomaterials and activation of the host immune system ( $\mathrm{Hu}$ et al., 2001; Moyano et al., 2012). The conformational change of adhesion proteins on the biomaterial surface may be one of the reasons for the occurrence of adverse response. For instance, the foreign body reaction, inflammation, and the exposure of hidden structures and sequences of adhesion proteins allows them to act as receptors for the binding of inflammatory or immune cells to the surface (Thevenot et al., 2008). Innate immune cells are able to recognize invaders and induce an immune response through pattern recognition receptors (PRPs) (Brubaker et al., 2015), based on the combination of PRPs and ligands [pathogen-associated molecular patterns (PAMPs) (Janeway, 1989); damage-associated molecular patterns (DAMPs) (Matzinger, 1994)]. Hydrophobicity is considered to be a DAMP, in other words, the hydrophobic property of a biomaterial is its inherent immunogenicity, which may initiates constructive remolding or scar tissue formation (Seong and Matzinger, 2004). It has been found that hydrophobic biomaterial surfaces selectively interact with CD8 $+\mathrm{T}$ lymphocytes, while hydrophilic/neutral surfaces tend to interact with CD4+ T lymphocytes (Chang et al., 2009). The hydrophilicity and hydrophobicity of a biomaterial can regulate the behavior of immune cells (Brodbeck et al., 2002; Jones et al., 2007), and the effects on tissue repair need to be further explored. To minimize adverse events triggered by the immunogenic of hydrophobic biomaterial surfaces, the hydrophilic molecules polyethylene oxide (PEO) and polyethylene glycol (PEG) are often used as biomaterial coatings to reduce surface protein adhesion and increase hydrophilicity (Tiller et al., 2001; Drury and Mooney, 2003). These coatings can also prevent implantation-related infection and biofilm formation (Busscher et al., 2012). It has also been reported that the hydrophilicity of biomaterial can be improved by adjusting the content of graphene oxide (GO), which improved in correspondence to an increase of GO (Aidun et al., 2019; Jabari et al., 2019).

Chemical groups are another important surface characteristic of biomaterials, with amino $\left(-\mathrm{NH}_{2}\right)$, carboxyl $(-\mathrm{COOH})$, hydroxyl $(-\mathrm{OH})$, and methyl $\left(-\mathrm{NH}_{3}\right)$ groups being commonly explored. These chemical moieties have a significant effect on the host response to biomaterials. Surfaces with hydrophilic $-\mathrm{NH}_{2}$ or $-\mathrm{OH}$ groups (positively and neutrally charged, respectively) strongly stimulated inflammatory cell recruitment and the fibrotic response in vivo (Kamath et al., 2008). While surfaces with hydrophobic, neutral $-\mathrm{NH}_{3}$ groups induced a more severe inflammatory response, and hydrophilic surfaces with - $\mathrm{COOH}$ groups (negatively charged) resulted in reduced cell infiltration and a milder inflammatory reaction (Barbosa et al., 2003, 2006; Barbosaa et al., 2004; Nair et al., 2008). These different results suggest that the $-\mathrm{NH}_{3}$ surface can eliminate the adsorption of leukocytes and reduce the immune reaction (Sperlinga et al., 2005). It has also been shown that $-\mathrm{NH}_{2}$ groups shift macrophage polarization toward an anti-inflammatory M2 phenotype and decrease the number of proinflammatory M1 macrophages, while -COOH groups yield the opposite result (Bartneck et al., 2010). This suggests that these findings cannot be explained by a single experimental model and may vary in vivo and in vitro. Based on the existing knowledge, studies have begun to use chemical groups to modify the surface of engineered scaffolds to facilitate repair and regeneration. 
A scaffold surface was modified with either $-\mathrm{NH}_{2}$ or $\mathrm{COOH}$, and it was found that both modified scaffolds could promote the adhesion and proliferation of adipose-derived stem cells (ADSCs). The difference was that scaffolds functionalized with $-\mathrm{NH}_{2}$ moieties promoted the osteogenic differentiation of ADSCs, while those functionalized with - $\mathrm{COOH}$ moieties promoted chondrogenic differentiation (Griffin et al., 2017). In terms of the ability to induce cell differentiation, - $\mathrm{OH}$ groups showed the strongest ability to induce osteogenic differentiation, followed by $-\mathrm{NH}_{2},-\mathrm{COOH}$, and $-\mathrm{NH}_{3}$ groups. Among them, $-\mathrm{NH}_{3}$ groups appeared to induce moderate myogenic differentiation (Keselowsky et al., 2004; Lan et al., 2005). Further studies revealed that $-\mathrm{NH}_{2}$-modified surfaces activate the extracellular signal-related kinase (ERK1/2) signaling pathway by promoting the expression of bone marrow stromal cell (BMSC) integrins to induce osteogenic differentiation (Bai et al., 2013). Further expanding the understanding of biomaterial surface characteristics and how biomaterials interact with host immune system is needed to more effectively repair damaged tissues (Damanik et al., 2014). In fact, biomaterial-mediated tissue repair and regeneration is influenced by a variety of factors, such as immune components of implant, immune milieu. The properties of biomaterials need to be more comprehensively understood for improved application.

\section{Natural Biomaterials}

The other type of biomaterials is natural biomaterials, including decellularized tissues, natural polymers, and cell-derived matrix. Compared to synthetic polymers, they are derived from biological tissues and are more suitable for cell adhesion, proliferation, differentiation and so on. Secondly, there are no acidic products. Natural polymers include polysaccharides (such as $\mathrm{HA}$, alginate, and chitosan) and proteins (gelatin, silk fibroin, and fibrin), are widely used in the production of scaffolds for cartilage regeneration. Due to their origins, These materials are characterized by high biocompatibility, bioactivity, and the degradation products are non-toxic; but, their low mechanical stability, rapid degradation, and poor stability greatly limits their applications (Wasyłeczko et al., 2020). For example, alginate based hydrogel scaffolds can support the growth and proliferation of enveloped chondrocytes and maintain their chondrocyte morphology, but they have poor stability and loss of mechanical strength in a short period of time (Bao et al., 2020). Secondly, alginate has low cell adhesion and cell interaction ability. Compared with other natural synthetic polymers, the main advantage of silk fibroin is its good strength and toughness, which is more suitable for the preparation of load bearing tissue engineering such as cartilage regeneration (Kundu et al., 2013). Gelatin was modified by methacrylate anhydride, and the prepared product methacrylamide enhanced the mechanical properties and degradation rate of gelatin, which makes it play an important role in the application of cartilage tissue engineering (Han et al., 2017). Unfortunately, these natural polymers are difficult to achieve hyaline cartilage regeneration, but rather non-valuable fibrocartilage. Natural biomaterials are favored by a wide range of researches, especially naturally derived ECM biomaterials. Decellularized ECM is considered to be the best choice because it can provide a microenvironment similar to natural ECM and further modulate the cellular behavior and function.

\section{Rationale for Using Extracellular Matrix (ECM) as Biomaterial}

The optimal scaffold biomaterial should be able to provide an environment like that in which tissue-resident cells survive, i.e., the ECM. It is a precise and orderly structural network composed of large molecules such as proteins and polysaccharides. The ECM provides physical structure, and the basic biochemical and biomechanical signals for regulating tissue morphology, differentiation and homeostasis (Wang et al., 2018; Nie et al., 2020). Tissue engineering technology is to mimic the structure and composition of the damaged tissue, providing an optimal environment for cell survival, cell-cell and cell-tissue interactions and signal transduction. The fabrication of functionalized scaffolds with biological activity made of natural biomaterials is undoubtedly a promising approach (Feng et al., 2020; Vainieri et al., 2020). Natural biomaterials such as dECM and natural polymers (collagen, silk fibroin, alginate, and chitosan) show repair potential in animal models of cartilage lesion (Dai et al., 2019; Pérez-Silos et al., 2019; Singh et al., 2019). Tissue (or organ) from various species after decellularization can be utilized for the repair of a damaged tissue (Sun et al., 2018; Lindberg et al., 2019). Such as there are studies have successfully used acellular human umbilical cord Wharton's jelly as a biomaterial to repair articular cartilage (Zhao et al., 2018).

Natural biomaterials are being explored and applied increasingly extensively. The mechanism of the natural biomaterial-driven tissue remolding remains to be elucidated, and adverse immune responses after implantation is a great challenge hindering application (Wu et al., 2019). Because of natural composition and structure, natural biomaterials elicit different host responses than others. There is a growing body of evidence suggesting that the host immune response to a biomaterial not only affects its function but must also be the primary factor determining the success of the repair. The issue of the host immune response induced by natural biomaterials, especially dECM, is reviewed below.

\section{Remove Immune Components via Decellularization}

In recent decades, the decellularization of tissues (or organs) has been developed and applied as an emerging technology in tissue engineering and regenerative medicine. The main purpose of the decellularization process is to remove immune components (such as cells and nuclear materials), while preserving the natural structure and biochemical components. Acellular ECM has good biocompatibility and biological activity. Similar to the natural matrix environment, acellular ECM can regulate the biological function of resident cells and multifunctional stem cells and promote the recovery of the structure and function of the damaged tissue (Agrawal et al., 2010; Li et al., 2018). In addition to its application in the repair of articular cartilage, acellular ECM has been applied in various tissues (or organs) such as bone (Huber et al., 2017), tendon (Zhang S. et al., 2018), nerve (Chen et al., 2019), blood vessels (Gong et al., 2016), cornea 
(Chakraborty et al., 2019), and skin (Milan et al., 2019), and some success in achieving repair.

\section{Evaluate the Decellularize Degree of ECM}

The host immune response to natural biomaterial can be activated by cell surface markers, residual DNA, alpha-Gal epitopes, and major histocompatibility complexes (MHCs), among others (Sutherland et al., 2015). Few researchers have studied the immunogenicity of allogeneic or xenogeneic cartilage-derived biomaterials. Cartilage tissue is considered to be "immune privilege" and does not elicit an host immune response. Studies have shown that unsatisfying outcomes are still caused by cartilage-derived biomaterials in vivo. The decellularization of tissues (or organs) is typically achieved using one or a combination of the following approaches: chemical (Ventura et al., 2019), physical (Schneider et al., 2016), and enzymatic (Luo et al., 2015; Li et al., 2019c). Decellularization technology broadens the source of biomaterials by reducing immune components. Compared to other tissues, the cartilage ECM is dense and difficult to decellularize (Gong et al., 2011). Insufficient decellularization easily leads to excessive residual immunogenic components. While intense decellularization will result in damage to the ECM ultrastructure and the loss of composition (Gilpin and Yang, 2017; Shen et al., 2020). Both run counter to the purpose of decellularization. Although a large number of studies have claimed to be able to achieve effective decellularization, there are still residual cellular constituents (Elder et al., 2010; Luo et al., 2015; Roth et al., 2017; Ghassemi et al., 2019; Bordbar et al., 2020). Effectively balancing the removal of immune components with the destruction of the ECM ultrastructure (or the loss of ECM components), and determining the impact of residual substances on host-biomaterial interactions remain long-debated topics. There is still a large gap in the understanding of the innate and adaptive immune responses resulting from the application of $\mathrm{dECM}$, as well as the role of macrophages and other immune cells in the remodeling of dECM.

Residual cellular material within the ECM may contribute to cytocompatibility problems, and some even led to acute or chronic inflammation (Brown et al., 2009; Nagata et al., 2010; Zhang et al., 2010). The probability of such adverse events can be reduced to some extent through decellularization. Currently, there are no uniform criteria for measuring the degree of decellularization. Most researchers have accepted the following minimum criteria to satisfy the intent of tissue decellularization: (1) the content of double-stranded DNA (dsDNA) should be $<50$ ng per mg ECM dry weight; (2) the length of DNA fragments should be <200 bp; and (3) staining with 4',6-diamidino-2phenylindole (DAPI) or H\&E should indicate the lack of visible nuclear material in tissue sections (Crapo et al., 2011). Badylak et al. (2008) proposed these conditions based on the outcomes of research in which an in vivo constructive remodeling process was observed, while adverse events were avoided. Of course, these guidelines are not sacrosanct and can differ depending on tissue type, implantation site and host immune function. There is still a lack of a clear scientific basis to establish optimal criteria, and most studies based on decellularization have been evaluated according to the universal criteria described above. The success or failure of any implanted material is related to the host immune system, and host innate or adaptive immune cells will respond to the cellular content, DNA and other immune components of the ECM (Badylak and Gilbert, 2008; Keane and Badylak, 2015).

Residual immunogenic substances in biomaterials resulted from mildly or inadequately decellularized matrix may have proinflammatory effects, which are associated with poor tissue remodeling outcomes (Brown et al., 2009). The focus on nucleic acids in the criteria for decellularization is reasonable, as residual DNA is directly associated with adverse host reactions (Zheng et al., 2005; Nagata et al., 2010). Numerous commercial products composed of dECM are now available for clinical use, such as Restore $^{\circledR}$, GraftJacket ${ }^{\circledR}$, TissueMend ${ }^{\circledR}$, Oasis ${ }^{\circledR}$, and Alloderm ${ }^{\circledR}$. Although most commercial products still contain DNA, the effect of the clinical application of these products is positive to a large extent. The residual DNA content is below $50 \mathrm{ng} / \mathrm{mg}$ ECM dry weight, or even lower, which is not enough to cause adverse host reactions that interfere with tissue remodeling (Gilbert et al., 2009).

Residual DNA is usually present in small fragments, which reduces the likelihood that it will play any substantial role in an adverse tissue remodeling response. In the majority of biomaterials used in the clinic, residual DNA consists of fragments that are less than $300 \mathrm{bp}$ in length, and seems to be too short to be of concern. In addition to the low content and short length of residual DNA, degradation of the DNA along with the ECM is another important reason that undesirable host reactions can be avoided in vivo, especially for some uncross-linked ECM materials that degrade rapidly. One of the important reasons why DNA fragments are required to be less than $200 \mathrm{bp}$ as a minimal criterion of decellularization may be that the chromosomal DNA of apoptotic cells is autonomously degraded into $180 \mathrm{bp}$ nucleosomal units by caspase-activated DNase (CAD). This DNA is then phagocytosed by macrophages and further degraded by deoxyribonuclease II (DNase II) in lysosomes (Kawane et al., 2003). The accumulation of undigested $180 \mathrm{bp}$ fragmented DNA in macrophages causes them to produce proinflammatory cytokines, such as IFN- $\beta$ and TNF- $\alpha$ (Yoshida et al., 2005; Kawane et al., 2006). TNF- $\alpha$ may be linked to the development of polyarthritis (Kawane et al., 2006). Additionally, residual DNA is recognized by macrophages as a DAMP through TLRs, especially TLR9 (Hemmi et al., 2000; Zhang et al., 2010; Ohto et al., 2015). Related studies have shown that macrophages can be activated by DNA fragments as small as 24 bp (Karayel et al., 2009; Aamodt and Grainger, 2016). Thus, the current threshold for residual DNA in decellularized tissues does not seem to be ideal, and it serves more as a benchmark established to aid research. As innate immune cells, macrophages participate in the host response to biomaterials in the early stage, and the phenotype of macrophage is significantly associated with tissue remodeling. As mentioned previously, DNA may be one cause of skewed polarization toward an M1 proinflammatory phenotype (Brown et al., 2009). Study found that more M1 proinflammatory macrophages adsorbed onto the dECM scaffold more residual content or longer DNA fragments, while the surroundings of the scaffold from which DNA was effectively eliminated were dominated by M2 antiinflammatory and remodeling macrophages (Keane et al., 2012). 
However, what is puzzling is the paucity of research on the interaction between macrophages and residual DNA in DECM. Obviously, there is a large gap in the understanding of the role of these molecules in the host response to dECM.

An in-depth investigation of macrophage-dECM interactions would be helpful in designing tissue engineering scaffolds more scientifically and rationally, thus enhancing the reparative effect and optimizing performance; further research is urgently needed.

\section{ROLE OF MACROPHAGES IN ECM-MEDIATED TISSUE REGENERATION}

\section{Critical Regulator and Effector Cell in Host-Biomaterial Interaction}

In tissue engineering, the host response to biomaterials is a key determinant of the success or failure of constructive tissue remodeling. The repair of damaged tissues using biomaterials is a complex process that involves the interaction of diverse immunological and biological systems. These activities do not occur randomly but as a series of finely regulated steps and events, which are correlated with the emergence of different cell types during distinct stages. The repair can be defined as wound healing, which is traditionally divided into many complex and overlapping stages, including coagulation and hemostasis, inflammation, proliferation and remodeling. Similarly, the host response to an implanted biomaterial involves the same steps observed in these stages. The ideal biomaterial should be able to modulate the different stages of the healing response by inducing a transition from inflammation and scar tissue formation to constructive remodeling and functional tissue recovery (Waters et al., 2017). ECM-derived tissue engineering biomaterials, unlike their synthetic counterparts, have been shown to prompt unique and constructive tissue remodeling (Sadtler et al., 2019). ECM has an immunomodulatory effect, particularly in terms of regulating macrophages-the key regulator and effector cells in the host response to biomaterials (Slivka et al., 2014; He et al., 2018). The phenotypical response of macrophages is a key factor in determining the outcome of downstream tissue remodeling (Brown et al., 2012b).

As previously described, macrophages begin to infiltrate in the early stage after implantation and become the primary immune cells in the host response to ECM-derived scaffolds after approximately 3-4 days (Brown et al., 2009). Recently, macrophages have gained extensive attention and been researched, and they are considered to be most relevant to tissue repair mediated by ECM-derived scaffolds. Previous studies have demonstrated the importance of macrophages in tissue reconstruction and regeneration, especially in applications involving tissue engineering biological scaffolds (Linares et al., 2016; Dai et al., 2018b, 2020; Zhang et al., 2020). Specifically, the process of ECM-mediated tissue remodeling depends on the activation of host macrophages toward the M2 phenotype, with anti-inflammatory and immunomodulatory functions (Dearth et al., 2016). At early points, a larger M2/M1 macrophage phenotype ratio predicts the later development of favorable organizational reconstruction (Brown et al., 2012a). Understanding the immunomodulatory effect of biological scaffolds provides potential guidance for the further development of ideal biomaterials to promote tissue repair and regeneration. Unfortunately, to date, the underlying mechanisms by which ECM-derived scaffolds modulate the macrophage phenotype shift from M1 to M2 are largely unknown.

\section{Phenotypic, Function and Plasticity Features of Macrophages}

Macrophages are a heterogeneous cell population with various functional phenotypes that participate in a variety of biological processes, including tissue homeostasis, inflammation, disease progression, and functional reconstruction. Human peripheral blood monocytes can be differentiated into macrophages (M0) and then polarized to different phenotypes. Macrophage phenotypes have been classified along a spectrum ranging from M1 (classically activated, proinflammatory) to M2 (alternatively activated, anti-inflammatory, immunomodulation, remodeling), with multiple subclasses (Martinez and Gordon, 2014; Alvarez et al., 2016). The nomenclature is similar to that used for Th1/Th2 lymphocytes (Mills et al., 2000). These diverse phenotypes can be distinguished by cell surface markers (CD molecules), secreted cytokines and effector molecules, and the metabolism of arginine (Anderson and Jones, 2007). M1 macrophages, the classical proinflammatory phenotype, are known to be activated by IFN- $\gamma$ alone or in combination with LPS or GM-CSF (Tarique et al., 2015). These cells are able to secrete a series of proinflammatory factors, including TNF- $\alpha$, IL-1 $\beta$, IL-6, IL-12, and IL-23 (Lopa et al., 2015). Additionally, M1 macrophages can produce reactive oxygen species (ROS) and present antigens and are inducers and effectors of the Th1 inflammatory response (Mosser, 2003). M1 macrophages produce high levels of inducible nitric oxide synthase (iNOS), leading to the metabolism of arginine into nitric oxide (NO). In contrast, "alternatively activated" M2 macrophages are anti-inflammatory and promote constructive tissue remodeling. M0 macrophages are polarized to the M2 phenotype by exposure to a variety of signals, including the cytokines IL-4 (classical M2-polarizing factor) and IL-13, immune complexes, and matricryptic peptides released during the degradation of ECM-derived scaffolds (Sicari et al., 2014). M2 macrophages are characterized by the secretion of IL-10, chemokine (CCL)-1, CCL-18, and TGF- $\beta$ (Fahy et al., 2014; Manferdini et al., 2017), the expression of high levels of scavenger, galactose and mannose receptors (e.g., CD206), and promotion of the Th2 response (Mills et al., 2000). Unlike the metabolism of arginine in M1 macrophages, in M2 macrophages, highly expressed arginase (Arg-1) metabolizes it to ornithine and polyamines instead of NO. According to its specific markers and functions, the M2 subphenotype can be further divided into four different subclasses (M2a, M2b, M2c, and M2d) (Ryszer, 2015; Yue et al., 2017), which are often overlooked and regarded as a single group. The functions of the M2 subtypes and others are shown in Table 1. Table 1 summarizes information related to 
TABLE 1 | Summary of macrophage subtypes and functions.

\begin{tabular}{|c|c|c|c|c|c|}
\hline Macrophage phenotype & Inducers & Expressed markers & Secreted molecules & Functions & References \\
\hline \multirow[t]{2}{*}{ M1 } & IFN- $\gamma$, LPS, GM-CSF & $\begin{array}{l}\text { CD80, CD86, CD68, } \\
\text { CCR7 }\end{array}$ & $\begin{array}{l}\text { TNF- } \alpha, \text { IL-1 } 1 \beta, \text { IL-6, } \\
\text { IL-12, IL-23, iNOS, } \\
\text { ROS, MMPs, VEGF }\end{array}$ & $\begin{array}{l}\text { Proinflammatory, tissue } \\
\text { damage, Th1-type } \\
\text { reaction }\end{array}$ & $\begin{array}{l}\text { Mosser, 2003; Verreck } \\
\text { et al., 2004; Lopa et al., } \\
\text { 2015; Tarique et al., } \\
\text { 2015; Qiu et al., } 2018\end{array}$ \\
\hline & IL-4, IL-13 & CD206, CD163 & $\begin{array}{l}\text { FIZZ1, Arg- } 1, \text { TGF- } \beta \text {, } \\
\text { CCL-18 }\end{array}$ & $\begin{array}{l}\text { Tissue repair and } \\
\text { remodeling, } \\
\text { anti-inflammatory }\end{array}$ & $\begin{array}{l}\text { Spiller et al., 2014; } \\
\text { Raimondo and } \\
\text { Mooney, 2018; } \\
\text { Wiktorowicz et al., } \\
2019\end{array}$ \\
\hline $\mathrm{M} 2 \mathrm{~b}$ & $\begin{array}{l}\text { ICs, LPS, IL-1 } \beta \text {, TLR } \\
\text { ligand }\end{array}$ & IL-10R, CD86, CD163 & $\begin{array}{l}\text { IL-10, IL-1 } 1 \beta, I L-6 \text {, } \\
\text { TNF- } \alpha\end{array}$ & $\begin{array}{l}\text { Immunoregulation, } \\
\text { homeostasis }\end{array}$ & $\begin{array}{l}\text { Gerber and Mosser, } \\
\text { 2001; Yue et al., 2017; } \\
\text { Yang et al., } 2019\end{array}$ \\
\hline \multicolumn{6}{|l|}{ M2 } \\
\hline M2c & $\begin{array}{l}\text { IL-10, TGF- } \beta \text {, } \\
\text { glucocorticoid }\end{array}$ & CD163, CD206 & $\begin{array}{l}\text { TGF- } \beta, \text { Arg- } 1 \text {, CCL-16, } \\
\text { CCL-18, MMPs }\end{array}$ & $\begin{array}{l}\text { Pro-wound healing, } \\
\text { matrix deposition, } \\
\text { tissue remodeling }\end{array}$ & $\begin{array}{l}\text { Zizzo et al., 2012; } \\
\text { Spiller et al., 2014; } \\
\text { Waters et al., 2017; } \\
\text { Becker et al., } 2018\end{array}$ \\
\hline M2d & TLR ligand, adenosine & VEGF, IL-12 low & IL-10, VEGF & Angiogenesis & $\begin{array}{l}\text { Grinberg et al., 2009; } \\
\text { Ferrante and Leibovich, } \\
2012\end{array}$ \\
\hline
\end{tabular}

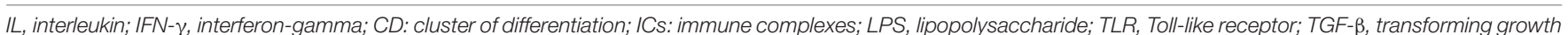

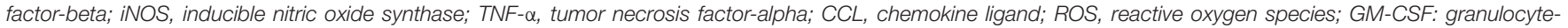

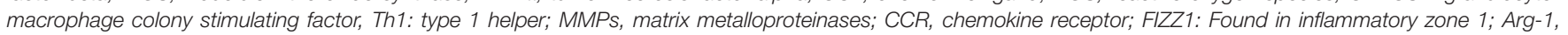
arginase-1; VEGF, vascular endothelial growth factor.

the M1 and M2 phenotypes, including the inducers, expressed markers, secreted molecules and functions.

\section{Promote Tissue Regeneration by Modulate Macrophage Polarization}

Significant effort has been made to regulate macrophage polarization using biomaterial and scaffold design strategies to promote tissue regeneration, which is known as immunoinformed techniques. It is hoped that the development of biomaterials that can stimulate the polarization of macrophages toward reparative functional phenotypes is becoming a research hotspot (Spiller et al., 2015). Designing a biomaterial with immunomodulatory function is a practical and efficient strategy. One study investigated the immunomodulatory properties of fabricated biomimetic with a bone-like staggered nanointerface during bone regeneration, and it was found that the hierarchical nanointerface possess the ability to facilitated M2 macrophage polarization to promote endogenous bone regeneration (Jin et al., 2019). Controlling the macrophage polarization by manipulating the nanomorphology of biomaterial surface may be an effective way to improve the performance of biomaterials (Ma et al., 2014). MSCs exosomes-mediated response in cartilage repair was also found to be associated with regenerative M2 macrophages (Zhang C.H. et al., 2018). In designing an immune-informed regenerative biomaterial, the most targeted approach to modulate macrophage polarization is to release factors (such as IL-4, IL10) that direct polarization, and this can be achieved through a controlled release system (Sridharan et al., 2015; Li M. et al., 2020).
Extracellular matrix-based scaffolds exhibit such immunoregulation potential, and the resulting constructive remodeling response is associated with a timely transition of the macrophage phenotype from proinflammatory M1 to immunomodulatory and constructive M2 (Sicari et al., 2014; Wu et al., 2019). Both the classically and alternatively activated macrophage phenotypes are transient and difficult to define, which means that macrophages can polarize into diverse phenotypes based on changes in the microenvironment (Tarique et al., 2015). The microenvironment in which biomaterials are implanted in vivo is complex, and macrophages are exposed to a variety of stimuli, including various cytokines and effectors secreted by host immune cells (Kimura et al., 2016), immune components, biochemical cues (e.g., surface chemical and composition) (Palmer et al., 2014; Hotchkiss et al., 2018) and biophysical cues (e.g., topography, stiffness, and pore size) (Madden et al., 2010; Bartneck et al., 2012; Abaricia et al., 2020) of biomaterials or scaffolds, and degradation products (Sicari et al., 2014). The activation and phenotypical polarization of macrophages in vivo is modulated by multiple factors. These factors should be taken into account in the design of future tissue engineering bioscaffolds to regulate the host response in a direction that favors constructive tissue remodeling (e.g., polarization of macrophages toward an M2 phenotype) (Garg et al., 2013; Alvarez et al., 2016).

The implantation of a biomaterial can induce a host response, which determines the outcome of constructive remodeling of the damaged tissue. The mechanism of ECM derived scaffolds mediate immunomodulation (e.g., the macrophage phenotype shifts from $\mathrm{M} 1$ to $\mathrm{M} 2$ ) in vivo is still unclear (Mimura et al., 2016; Huleihel et al., 2017). Moreover, not all ECM 
scaffolds derived from diverse source tissues can induce this phenomenon. The effect of ECM scaffolds derived from eight different source tissues (all porcine) on the polarization of macrophages was investigated. Macrophages exposed to ECM from the small intestinal submucosa, urinary bladder, brain, esophagus, and colon expressed a predominantly M2 phenotype. Conversely, macrophage exposure to dermal ECM resulted in a predominantly M1 phenotype, whereas liver ECM and skeletal muscle ECM did not significantly change the phenotype of the macrophages (Dziki et al., 2017). It is notable that some studies on regulation of the macrophage phenotype by ECM have conflicting results (Meng et al., 2015). Different decellularization protocols are applied to each tissue, which makes the analysis more complicated. In addition, unique ECM components from diverse source tissues make the seemingly contradictory results somewhat reasonable. Despite the marked differences and heterogeneity among various macrophage subtypes, their phenotype is highly plastic and dynamic (Hume, 2015). In fact, macrophage phenotypes exist in a range, with $\mathrm{M} 1$ and M2 as extreme values. Any given cell can express or co-express characteristics of the M1 or M2 phenotype, rather than exhibit a discrete functional state with a well-defined boundary (Mosser and Edwards, 2008). The description of macrophage activation and polarization is currently controversial and confusing, and the lack of a consensus diminishes the reference value of research and hinders progress to some extent. A guideline, published in 2014, will contribute to the better unification of experimental standards in future research (Murray et al., 2014). Although there is evidence that it is too simple to classify activated macrophages as M1 or M2, many studies in the literature have adopted these categories to illustrate specific findings. The simple classification of macrophages into M1 and M2 is inadequate, but it is useful for examining the inflammatory phenotype in response to biomaterials, especially when measuring the levels of inflammatory cytokines. The process of ECM-derived scaffolds facilitating tissue repair by regulating macrophage phenotypical transformation is complex. A clear and detailed report on distinguishing macrophage phenotypes will help analyze and understand this process. Modulating the components of the immune system to promote tissue regeneration. Once we have a clear understanding of host-biomaterial interactions, it will be possible to construct suitable immuno-informed decellularized tissue that can control tissue remodeling and initiate beneficial reprogramming in vivo (Taraballi et al., 2018).

\section{ARTICULAR CARTILAGE ECM (AC-ECM)}

\section{Rich in Collagen}

Articular cartilage ECM (AC-ECM) is a biomaterial widely studied in cartilage tissue engineering at present. It has good biocompatibility and is very similar to the natural cartilage matrix in terms of composition. AC-ECM scaffolds support cell adhesion and proliferation and are able to recruit autologous endogenous stem cells and induce their differentiation toward chondrocytes in vivo, allowing them to maintain the chondrocyte phenotype and thus achieving the in situ regeneration of cartilage (Xue et al.,
2012; Almeida et al., 2016; Nasiri and Mashayekhan, 2017; Li et al., 2019a). The main components of AC-ECM are Col II and proteoglycans, and Col II accounts for over $80 \%$ of the dry weight of AC-ECM. The collagen network is essential in determining the mechanical properties of cartilage, and small amounts of other collagen types (I, III, V, VI, IX, X, and XI) also exist in AC-ECM (Gannon et al., 2015a,b; Campos et al., 2019; Wang et al., 2020a). Col II plays a vital role in the development and maturation of chondrocytes. It has an immunomodulatory effect, relieving the degeneration of cartilage matrix in OA by inhibiting the STAT1 signaling pathway of proinflammatory macrophages (Dai et al., 2018a). Macrophages express prochondrogenic cytokines, which stimulate chondrocytes to secrete matrix components while activating glycine receptors and reducing the intracellular calcium concentration to inhibit chondrocyte apoptosis and hypertrophy (Dai et al., 2018b). In short, both AC-ECM and Col II-based engineering scaffolds have great potential for the repair of damaged cartilage.

However, what is often overlooked and worrying is that $\mathrm{Col}$ II has immunogenicity and can induce arthritis by emulsification with an adjuvant, which is known as collagen-induced arthritis (CIA) (Trentham et al., 1977). The following discussion of this problem is mainly focused on the frequently studied ACECM scaffold.

\section{Antigenic and Immunogenic Responses to Collagen}

Before discussing the immunochemical property of any protein, it is important to draw a distinction between the potentially ambiguous terms "antigenicity" and "immunogenicity." Although it is difficult to make such a distinction due to the presence of a number of extrinsic factors, and for the purpose of the present discussion, the following simple distinction is adopted: antigenicity will be used to refer to the ability of a substance to interact with antibodies or cellular receptors, whereas immunogenicity will be used to refer to the ability to induce an immune response-a process that includes antibody synthesis and interaction. Therefore, we can think of any biomaterial that has immunogenicity to also have antigenicity.

Collagen is considered to be a safe and multifunctional biomaterial, but it has also raised concerns regarding its potential to elicit an immune response. Although the clinical incidence of adverse reactions to collagen implants is low, this do occur. Previously, it was widely accepted that collagen is an inert protein and does not have immunogenicity. Later studies have shown that it can interact with antibodies, but still regarded as a weak antigen. In tissue engineering, the interpretation of the immunogenicity of collagen-based scaffolds is often complicated by the presence of other non-collagen components, including cellular and nuclear contents, MHCs, and alpha-Gal epitopes, among others (Wong and Griffiths, 2014; Sutherland et al., 2015). Currently, few studies have targeted the immunological properties of collagen. Due to most collagenbased scaffolds were composed of type I collagen (and a small amount of type III collagen), which is generally not thought to evoke a potentially adverse host immune response (Bayrak 
et al., 2013; Shetty et al., 2013; Yuan et al., 2014). However, as research progresses to address the issue of cartilage repair and regeneration, AC-ECM (enriched with Col II) and marine collagen (extracted from marine organisms) have shown good prospects for application and thus received increasing attention from researchers (Pustlauk et al., 2016; Tamaddon et al., 2017; Dai et al., 2018b). Allogeneic or xenogeneic Col II can induce arthritis (i.e., CIA) when emulsified with an adjuvant. Therefore, the immunological property of collagen has once again raised concern, which will be described in detail below.

Trentham et al. (1977) first discovered that emulsified Col II could induce arthritis and established an experimental arthritis model-a CIA model (Trentham et al., 1977). CIA is the most extensively studied model of rheumatoid arthritis (RA), mainly involving distal joints (especially the posterior ankle joint) ( $\mathrm{Wu}$ et al., 2015). Its pathological features are similar to those of RA, including synovial hyperplasia, inflammatory cell infiltration, and cartilage destruction (Scarneo et al., 2019; De et al., 2020). Col II is the major protein in the cartilage of joints targeted by RA, and anti-Col II autoantibodies are present in the serum of RA patients, which indicates that Col II can induce an autoimmune response of an arthritic nature in the body (Manivel et al., 2015). There is some evidence that antibodies in RA patients target the same Col II molecular regions as in those in CIA (Burkhardt et al., 2002). In addition, the presence of $T$ and $B$ cell immunity has also been reported (Dimitrijević et al., 2020), but it is not clear whether this is a pathogenic factor or result of RA. Recent studies have also shown that the immune response may be involved in the development of OA. When inflammation occurs on the surface of articular cartilage for some reason, various components (mainly Col II) are exposed and thus stimulate B lymphocytes to produce anti-Col II antibodies, resulting in an immune response in OA. Therefore, as a biomaterial in cartilage tissue engineering, whether AC-ECM rich in Col II will cause an intraarticular immune reaction has become a concern. The mechanism of CIA is still unclear, but it is certainly inextricably linked to the structural characteristics of Col II.

A Col II molecule consists of three identical $\alpha_{1}$ chains (a homotrimer), each containing 1487 amino acids with a molecular weight of approximately $130 \mathrm{kDa}$ (Miller, 1971). Each of the three $\alpha_{1}$ chains forms a left-handed helix by itself and then further intertwines to form a right-handed triple-superhelical structure, which is the main and unique structural region of the molecule, known as the "triple-helical domain." The greatest feature of the "triple-helical domain" is the periodically repeated arrangement of amino acids presenting $[\mathrm{Gly}-\mathrm{X}-\mathrm{Y}]_{n}$, in which the positions of $\mathrm{X}$ and $\mathrm{Y}$ are usually occupied by proline (Pro) and hydroxyproline (Hyp), respectively (Canty and Kadler, 2005). Each chain has a short peptide extension at each end of the helix, the telopeptide (i.e., the amino (N)- and carboxyl (C)telopeptides), which is a non-helical structure and does not contain Gly-X-Y repeats (Liu et al., 2015). The telopeptide region determines the intermolecular interactions that contribute to (and stabilize) normal fiber assembly. The amino acid sequences of telopeptides may vary from species to species, while certain cross-linked regions involved in fiber formation are highly conserved. Once secreted into the ECM, collagen molecules will be arranged head to tail in a quarter-stagger array and then covalently cross-linked into fibers through polymerization and disulfide bonds, forming the skeleton of the cartilage matrix. The structures of the Col II molecule and assembled fibrils are shown in Figure 2A.

The antigenic epitopes that determine the immunogenicity of Col II can be divided into three main categories: (1) those located the non-helical terminal regions (telopeptides), existing in both natural and denatured collagen; (2) those dependent on the amino acid sequence of the helical region of the molecule, exposed after this region is unwound and thus present in denatured collagen; and (3) those dependent on the triple-helical conformation, which only exist in natural collagen as the integrity of the triple helix must be maintained (Figure 2B). Sequence homology is highly conserved in the helical portion of Col II among different species, and the degree of change in the amino acid sequence is less than a few percent. Hidden epitopes (such as amino acid sequences in the helical region) interact with antibodies when the triple helix is unwound (Dodge and Poole, 1989). This fact may have implications for the host immune response to AC-ECM implants as they denature and degrade. The degree of telopeptide variation is much greater, which is considered to be the main determinant of Col II immunogenicity. Some studies have tried to reduce the immunogenicity by using proteolytic enzymes (e.g., pepsin) to remove the terminal telopeptides, resulting in what is known as Atelocollagen (Lin and Liu, 2006; Jeevithan et al., 2015; Figure 2B). However, there is still a lack of scientific evidence regarding the effect of this treatment on collagen immunogenicity. It should be made clear that pepsin treatment does not completely remove telopeptides. Furthermore, although this process cannot disrupt the triplehelical structure, the destruction of fiber networks will reduce the mechanical properties of collagenous implants (Shayegan et al., 2016). In the absence of a clear immunological benefit obtained by Atelocollagen, the other two types of antigenic epitopes of collagen molecules cannot be ignored.

It should be clarified that Col II-induced arthritis (CIA) develops slowly with the aid of an adjuvant, thus stimulating a high and persistent antibody response, which can be interpreted as an amplification effect. AC-ECM derived scaffolds usually undergo cross-linking, which delays the degradation of the scaffold and appears to have an effect similar to that of adjuvant. Col II is capable of inducing CIA in different species, but the sensitivity to Col II varies among species. Despite the fact that some implants containing Col II did not elicit adverse immune reactions in animal models (Nehrer et al., 1998; Mainil-Varlet et al., 2001), none of these studies were conducted in species previously shown to be susceptible to CIA. Although there is no evidence to support the theory that the implantation of biomaterials containing Col II could induce autoimmunity, there is also no direct evidence to disprove this theory.

\section{Discussion of Potential Immune Response to AC-ECM}

Articular cartilage ECM derived scaffolds are typically obtained in two ways: the granulation of cartilage by chopping or crushing, 


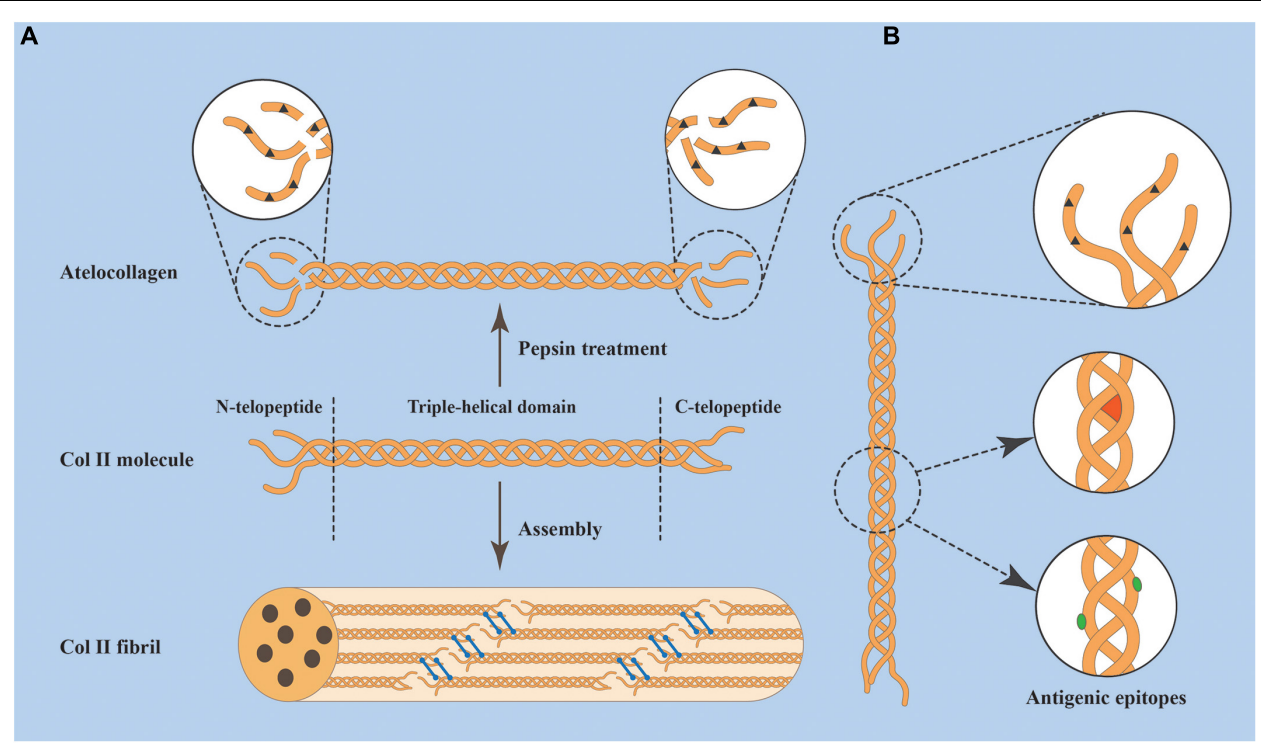

FIGURE 2 | (A) Three $\alpha_{1}$ chains intertwine to form a type II collagen (Col II) molecule, which consists of three parts: a triple-helical domain and N- and C-telopeptides. Collagen molecules spontaneously assemble into fibrils head to tail in a quarter-stagger array and are stabilized by covalent bonds (blue bars). The molecule can be treated with pepsin to remove (not completely remove) telopeptides, yielding Atelocollagen. (B) Antigenic epitopes of Col II include those located within the telopeptides (dark brown triangles), those located in the helical region and dependent on the conformation (red sector), and those located in the helical region and dependent on the amino acid sequence (green ovals).

followed by decellularization and cross-linking to produce a highly porous customized scaffold structure, but at the expense of mechanical properties (Yang et al., 2008; Browe et al., 2019). Or the decellularization of intact cartilage explants without complete disruption of the collagen network, with relatively better mechanical properties but a very low porosity that limits the infiltration of cells (Schwarz et al., 2012; Li et al., 2019c). To some extent, these two kinds of scaffolds may alter the immune response induced by Col II. The purification of commercial collagen products is usually conducted at $4^{\circ} \mathrm{C}$ to prevent denaturation, a requirement apparently not met in the preparation of AC-ECM derived scaffolds. Whether Col II in AC-ECM derived scaffolds retains its natural structure, whether the decellularization process leads to the exposure of antigenic epitopes and whether cross-linking can hide antigenic epitopes remains unknown. In contrast to pure Col II-derived scaffolds, AC-ECM derived scaffolds contain other components such as GAGs that wrap around Col II, which may hide its antigenic determinants. These questions remain to be answered by followup research. An in-depth understanding of the immunological properties of Col II-containing scaffolds and their impact on cartilage will lay a foundation for the more scientific design of optimal scaffolds for use in cartilage tissue engineering.

\section{CONCLUDING REMARKS AND FUTURE PERSPECTIVES}

Nowadays, a wide variety of biomaterials are used for the repair of cartilage and other tissues in tissue engineering. However, most of biomaterials do not function as expected, or some even lead to the occurrence of adverse events. These unsatisfactory results are mainly due to the adverse interaction between the implanted biomaterials and the host's immune system. The host-biomaterial interaction is crucial to determining the outcome of downstream tissue reconstruction. It is influenced by numerous factors, such as immune components of material, cytokines and inflammatory agents induce by implants. Macrophages are the critical immune regulators, and can promote inflammatory or facilitate repair and regeneration attributing to their plasticity and versatility. The relationship between tissue healing and the immune system is very complex, since immune components of material or the cells involved could drastically change the repair outcome. Modulating the immune system through immunomodulatory biomaterials to promote repair is an effective strategy in future tissue engineering.

In recent years, Col II-containing scaffolds, especially ACECM-derived scaffolds, have become a hot research topic. It is worth noting that Col II has immunogenicity and could induce arthritis (i.e., CIA), an issue that is easily overlooked by the public and has attracted our attention. In this paper, the immunological characteristics of Col II are analyzed, and the potential immunogenicity of Col II-containing biomaterials is summarized.

An in-depth exploration of the host immune response to biomaterials not only is critical to understanding the repair mechanisms of these biomaterials but also paves the way for the development of ideal cartilage repair biomaterials in the future. All kinds of biomaterials have been explored for their potential in cartilage repair, and some have shown good results, which largely depend on the host response to the implanted 
biomaterial. Biomaterials have been designed with a keen interest in the development of "passive biomaterials" to limit undesirable immune responses. Emphasis has been placed on promoting repair by preventing (or reducing) protein adhesion to the surface of the implanted biomaterial and the resulting inflammatory/immune cell activation and interaction. However, researchers have come to realize that the immune system plays a fundamental role in coordinating and defining the nature of the repair process. Allowing specific biological reactions is helpful for biomaterial-mediated remodeling. The link between the host response and tissue repair is complicated, and studies of hostbiomaterial interactions have mainly focused on macrophages. The concept of the optimal biomaterial is shifting from reducing the host response to triggering the desired immune response, thereby facilitating constructive remodeling. With the continuous development of tissue engineering and regeneration medicine, regulating the interaction between biomaterials and

\section{REFERENCES}

Aamodt, J. M., and Grainger, D. W. (2016). Extracellular matrix-based biomaterial scaffolds and the host response. Biomaterials 86, 68-82. doi: 10.1016/j. biomaterials.2016.02.003

Abaricia, J. O., Shah, A. H., Chaubal, M., Hotchkiss, K. M., and Olivares-Navarrete, R. (2020). Wnt signaling modulates macrophage polarization and is regulated by biomaterial surface properties. Biomaterials 243:119920. doi: 10.1016/j. biomaterials.2020.119920

Agrawal, V., Johnson, S. A., Reing, J., Zhang, L., Tottey, S., Wang, G., et al. (2010). Epimorphic regeneration approach to tissue replacement in adult mammals. Proc. Natl. Acad. Sci. U S A. 107, 3351-3355. doi: 10.1073/pnas.0905851106

Aidun, A., Firoozabady, A. S., Moharrami, M., Ahmadi, A., Haghighipour, N., Bonakdar, S., et al. (2019). Graphene oxide incorporated polycaprolactone/chitosan/collagen electrospun scaffold: enhanced osteogenic properties for bone tissue engineering. Artif. Organs 43, E264-E281.

Albright, J. C., and Daoud, A. K. (2017). Microfracture and microfracture plus. Clin. Sports Med. 36, 501-507. doi: 10.1016/j.csm.2017.02.012

Allen, L. T., Tosetto, M., Miller, I. S., O’Connor, D. P., Penney, S. C., Lynch, I., et al. (2006). Surface-induced changes in protein adsorption and implications for cellular phenotypic responses to surface interaction. Biomaterials 27, 30963108. doi: 10.1016/j.biomaterials.2006.01.019

Almeida, H. V., Eswaramoorthy, R., Cunniffe, G. M., Buckley, C. T., O’Brien, F. J., and Kelly, D. J. (2016). Fibrin hydrogels functionalized with cartilage extracellular matrix and incorporating freshly isolated stromal cells as an injectable for cartilage regeneration. Acta Biomater. 36, 55-62. doi: 10.1016/ j.actbio. 2016.03 .008

Alvarez, M. M., Liu, J. C., Santiago, G. T.-D., Cha, B.-H., Vishwakarma, A., Ghaemmaghami, A., et al. (2016). Delivery strategies to control inflammatory response: modulating M1-M2 polarization in tissue engineering application. J. Control. Release 240, 349-363. doi: 10.1016/j.jconrel.2016.01.026

Anderson, J. M., and Jones, J. A. (2007). Phenotypic dichotomies in the foreign body reaction. Biomaterials 28, 5114-5120. doi: 10.1016/j.biomaterials. 2007 . 07.010

Anderson, J. M., Rodriguez, A., and Chang, D. T. (2008). Foreign body reaction to biomaterials. Semin. Immunol. 20, 86-100. doi: 10.1016/j.smim.2007.11.004

Ang, L. T., Jennings, T. A., and Eaton, J. W. (1998). Mast cells mediate acute inflammatory responses to implanted biomaterials. Proc. Natl. Acad. Sci. U S A. 95, 8841-8846. doi: 10.1073/pnas.95.15.8841

Badylak, S. F., and Gilbert, T. W. (2008). Immune response to biologic scaffold materials. Semin. Immunol. 20, 109-116. doi: 10.1016/j.smim.2007.11.003

Badylak, S. F., Valentin, J. E., Ravindra, A. K., McCABE, G. P., and Stewart-Akers, A. M. (2008). Macrophage phenotype as a determinant of biologic scaffold remodeling. Tissue Eng Part A 14, 1835-1842. doi: 10.1089/ten.tea.2007.0264

Baena, J., Jiménez, G., López-Ruiz, E., Antich, C., Gri’án-Lisón, C., Perán, M., et al. (2019). Volume-by-volume bioprinting of chondrocytes-alginate bioinks the host must be a key part of the design and a focus of future work in this field. This future work will lead to developments that will hopefully promote the clinical translation of biomaterials.

\section{AUTHOR CONTRIBUTIONS}

All authors listed have made a substantial, direct and intellectual contribution to the work, and approved it for publication.

\section{FUNDING}

This work was supported by the National Key R\&D Program of China (2018YFC1105900) and the Chinese PLA General Hospital Medical Youth Program (QNC19042).

in high temperature thermoplastic scaffolds for cartilage regeneration. Exp. Biol. Med. 244, 13-21. doi: 10.1177/1535370218821128

Bai, B., He, J., Li, Y.-S., Wang, X.-M., Ai, H.-J., and Cui, F.-Z. (2013). Activation of the ERK1/2 signaling pathway during the osteogenic differentiation of mesenchymal stem cells cultured on substrates modified with various chemical groups. Biomed. Res. Int. 2013:361906.

Bao, W., Li, M., Yang, Y., Wan, Y., and Wang, X. (2020). Advancements and frontiers in the high performance of natural hydrogels for cartilage tissue engineering. Front. Chem. 8:53. doi: 10.3389/fchem.2020.00053

Barbosa, J. N., Barbosa, M. R., and Aguas, A. P. A. (2003). Adhesion of human leukocytes to biomaterials: an in vitro study using alkanethiolate monolayers with different chemically functionalized surfaces. J. Biomed. Mater. Res. A 65, 429-434. doi: 10.1002/jbm.a.10488

Barbosa, J. N., Madureira, P., Barbosa, M. A., and Águas, A. P. (2006). The influence of functional groups of self-assembled monolayers on fibrous capsule formation and cell recruitment. J. Biomed. Mater. Res. A 76, 737-743. doi: 10.1002/jbm.a. 30602

Barbosaa, J. N., Barbosa, M. A., and Aguas, A. P. (2004). Inflammatory responses and cell adhesion to self-assembled monolayers of alkanethiolates on gold. Biomaterials 25, 2557-2563. doi: 10.1016/j.biomaterials.2003.09.047

Bartneck, M., Heffels, K.-H., Pan, Y., Bovi, M., Zwadlo-Klarwasser, G., and Groll, J. (2012). Inducing healing-like human primary macrophage phenotypes by 3D hydrogel coated nanofibres. Biomaterials 33, 4136-4146. doi: 10.1016/j. biomaterials.2012.02.050

Bartneck, M., Keul, H. A., Singh, S., Czaja, K., Bornemann, J., Bockstaller, M., et al. (2010). Rapid uptake of gold nanorods by primary human blood phagocytes and immunomodulatory effects of surface chemistry. ACS Nano 4, 3073-3086. doi: $10.1021 / \mathrm{nn} 100262 \mathrm{~h}$

Bayrak, A., Prüger, P., Stock, U. A., and Seifert, M. (2013). Absence of immune responses with xenogeneic collagen and elastin. Tissue Eng. Part A 19, 15921600. doi: 10.1089/ten.tea.2012.0394

Becker, M., Maring, J. A., Schneider, M., Martin, A. X. H., Seifert, M., Klein, O., et al. (2018). Towards a novel patch material for cardiac applications: tissue-specific extracellular matrix introduces essential key features to decellularized amniotic membrane. Int. J. Mol. Sci. 19:20.

Benthien, J. P., and Behrens, P. (2013). Reviewing subchondral cartilage surgery: considerations for standardised and outcome predictable cartilage remodelling. Int. Orthop. 37, 2139-2145. doi: 10.1007/s00264-013-2025-z

Bordbar, S., Bakhshaiesh, N. L., Khanmohammadi, M., Sayahpour, F. A., Alini, M., and Eslaminejad, M. B. (2020). Production and evaluation of decellularized extracellular matrix hydrogel for cartilage regeneration derived from knee cartilage. J. Biomed. Mater. Res. A 108, 938-946. doi: 10.1002/jbm.a.36871

Brodbeck, W. G., Patel, J., Voskerician, G., Christenson, E., Shive, M. S., Nakayama, Y., et al. (2002). Biomaterial adherent macrophage apoptosis is increased by hydrophilic and anionic substrates in vivo. Proc. Natl. Acad. Sci. U S A. 99, 10287-10292. doi: 10.1073/pnas.162124199 
Brodbeck, W. G., Shive, M. S., Colton, E., Nakayama, Y., Matsuda, T., and Anderson, J. M. (2001). Influence of biomaterial surface chemistry on the apoptosis of adherent cells. J. Biomed. Mater. Res. 55, 661-668. doi: 10.1002/ 1097-4636(20010615)55:4<661::aid-jbm1061>3.0.co;2-f

Browe, D. C., Mahon, O. R., Díaz-Payno, P. J., Cassidy, N., Dudurych, I., Dunne, A., et al. (2019). Glyoxal cross-linking of solubilized extracellular matrix to produce highly porous, elastic, and chondro-permissive scaffolds for orthopedic tissue engineering. J. Biomed. Mater. Res. A 107, 2222-2234. doi: 10.1002/jbm.a.36731

Brown, B. N., Londono, R., Tottey, S., Zhang, L., Kukla, K. A., Wolf, M. T., et al. (2012a). Macrophage phenotype as a predictor of constructive remodeling following the implantation of biologically derived surgical mesh materials. Acta Biomater. 8, 978-987.

Brown, B. N., Ratner, B. D., Goodman, S. B., Amar, S., and Badylak, S. F. (2012b). Macrophage polarization: an opportunity for improved outcomes in biomaterials and regenerative medicine. Biomaterials 33, 3792-3802. doi: 10 . 1016/j.biomaterials.2012.02.034

Brown, B. N., Valentin, J. E., Stewart-Akers, A. M., McCabe, G. P., and Badylak, S. F. (2009). Macrophage phenotype and remodeling outcomes in response to biologic scaffolds with and without a cellular component. Biomaterials 30, 1482-1491. doi: 10.1016/j.biomaterials.2008.11.040

Brubaker, S. W., Bonham, K. S., Zanoni, I., and Kagan, J. C. (2015). Innate immune pattern recognition: a cell biological perspective. Annu. Rev. Immunol. 33, 257-290. doi: 10.1146/annurev-immunol-032414-112240

Burkersroda, F. V., Schedl, L., and Göpferich, A. (2002). Why degradable polymers undergo surface erosion or bulk erosion. Biomaterials 23, 4221-4231. doi: 10 . 1016/s0142-9612(02)00170-9

Burkhardt, H., Koller, T., Engström, Å, Nandakumar, K. S., Turnay, J., Kraetsch, H. G., et al. (2002). Epitope-specific recognition of type II collagen by rheumatoid arthritis antibodies is shared with recognition by antibodies that are arthritogenic in collagen-induced arthritis in the mouse. Arthritis Rheum 46, 2339-2348. doi: 10.1002/art.10472

Busscher, H. J., Mei, H. C. V. D., Subbiahdoss, G., Jutte, P. C., Dungen, J. J. A. M. V. D., Zaat, S. A. J., et al. (2012). Biomaterial-Associated infection: locating the finish line in the race for the surface. Sci. Transl. Med. 4:153rv10. doi: 10.1126/scitranslmed.3004528

Campos, Y., Almirall, A., Fuentes, G., Bloem, H. L., Kaijzel, E. L., and Cruz, L. J. (2019). Tissue engineering: an alternative to repair cartilage. Tissue Eng. Part B Rev. 25, 357-373. doi: 10.1089/ten.teb.2018.0330

Canty, E. G., and Kadler, K. E. (2005). Procollagen trafficking, processing and fibrillogenesis. J. Cell Sci. 118, 1341-1353. doi: 10.1242/jcs.01731

Chakraborty, J., Roy, S., Murab, S., Ravani, R., Kaur, K., Devi, S., et al. (2019). Modulation of macrophage phenotype, maturation and graft integration through chondroitin sulfate crosslinking to decellularized cornea. ACS Biomater. Sci. Eng. 5, 165-179. doi: 10.1021/acsbiomaterials.8b00251

Chang, D. T., Colton, E., Matsuda, T., and Anderson, J. M. (2009). Lymphocyte adhesion and interactions with biomaterial adherent macrophages and foreign body giant cells. J. Biomed. Mater. Res. A 91, 1210-1220. doi: 10.1002/jbm.a. 32218

Chaudhary, P., Pesacreta, T. C., and Misra, R. D. K. (2012). Interplay between protein-modified surface and functional response of osteoblasts. J. Biomed. Mater. Res. A 100, 3157-3166. doi: 10.1002/jbm.a.34232

Chen, S., Du, Z., Zou, J., Qiu, S., Rao, Z., Liu, S., et al. (2019). Promoting neurite growth and schwann cell migration by the harnessing decellularized nerve matrix onto nanofibrous guidance. ACS Appl. Mater. Interfaces 11, 1716717176. doi: 10.1021/acsami.9b01066

Chen, Y., Sui, J., Wang, Q., Yin, Y., Liu, J., Wang, Q., et al. (2018). Injectable self-crosslinking HA-SH/Col I blend hydrogels for in vitro construction of engineered cartilage. Carbohydr. Polym. 190, 57-66. doi: 10.1016/j.carbpol. 2018.02.057

Chrzanowski, W., Kondyurin, A., Lee, J. H., Lord, M. S., Bilek, M. M. M., and Kim, H.-W. (2012). Biointerface: protein enhanced stem cells binding to implant surface. J. Mater. Sci. Mater. Med. 23, 2203-2215. doi: 10.1007/s10856-0124687-2

Cipriano, A. F., Sallee, A., Tayoba, M., Alcaraz, M. C. C., Lin, A., Guan, R.-G., et al. (2017). Cytocompatibility and early inflammatory response of human endothelial cells in direct culture with $\mathrm{Mg}-\mathrm{Zn}-\mathrm{Sr}$ alloys. Acta Biomater. 48, 499-520. doi: 10.1016/j.actbio.2016.10.020

Collier, T. O., and Anderson, J. M. (2002). Protein and surface effects on monocyte and macrophage adhesion, maturation, and survival. J. Biomed. Mater. Res. 60, 487-496. doi: 10.1002/jbm.10043
Crapo, P. M., Gilbert, T. W., and Badylak, S. F. (2011). An overview of tissue and whole organ decellularization processes. Biomaterials 32, 3233-3243. doi: 10.1016/j.biomaterials.2011.01.057

Dai, L., He, Z., Jiang, Y., Zhang, X., Ren, S., Zhu, J., et al. (2019). One-step strategy for cartilage repair using acellular bone matrix scaffold based in situ tissue engineering technique in a preclinical minipig model. Am. J. Transl. Res. 11, 6650-6659.

Dai, M., Liu, X., Wang, N., and Sun, J. (2018a). Squid type II collagen as a novel biomaterial: isolation, characterization, immunogenicity and relieving effect on degenerative osteoarthritis via inhibiting STAT1 signaling in pro-inflammatory macrophages. Mater. Sci. Eng. C Biomim. Supramol. Syst. 89, 283-294. doi: 10.1016/j.msec.2018.04.021

Dai, M., Sui, B., Xue, Y., Liu, X., and Sun, J. (2018b). Cartilage repair in degenerative osteoarthritis mediated by squid type II collagen via immunomodulating activation of M2 macrophages, inhibiting apoptosis and hypertrophy of chondrocytes. Biomaterials 180, 91-103. doi: 10.1016/j.biomaterials.2018.07. 011

Dai, M., Sui, B., Hua, Y., Zhang, Y., Bao, B., Lin, Q., et al. (2020). A well defectsuitable and high-strength biomimetic squid type II gelatin hydrogel promoted in situ costal cartilage regeneration via dynamic immunomodulation and direct induction manners. Biomaterials 240:119841. doi: 10.1016/j.biomaterials.2020. 119841

Damanik, F. F. R., Rothuizen, T. C., Blitterswijk, C. V., Rotmans, J. I., and Moroni, L. (2014). Towards an in vitro model mimicking the foreign body response: tailoring the surface properties of biomaterials to modulate extracellular matrix. Sci. Rep. 4:6325.

De, S., Kundu, S., and Chatterjee, M. (2020). Generation of a robust model for inducing autoimmune arthritis in Sprague Dawley rats. J. Pharmacol. Toxicol. Methods 102:106659. doi: 10.1016/j.vascn.2019.106659

Dearth, C. L., Slivka, P. F., Stewart, S. A., Keane, T. J., Tay, J. K., Londono, R., et al. (2016). Inhibition of COX1/2 alters the host response and reduces ECM scaffold mediated constructive tissue remodeling in a rodent model of skeletal muscle injury. Acta Biomater. 31, 50-60. doi: 10.1016/j.actbio.2015.11.043

DeFife, K. M., Jenne, C. R., McNally, A. K., Colton, E., and Anderson, J. M. (1997). Interleukin-13 induces human monocyte/macrophage fusion and macrophage mannose receptor expression. J. Immunol. 158, 3385-3390.

Deng, M., Tan, J., Hu, C., Hou, T., Peng, W., Liu, J., et al. (2020). Modification of PLGA scaffold by MSC-Derived extracellular matrix combats macrophage inflammation to initiate bone regeneration via TGF-beta-Induced protein. $A d v$. Healthc. Mater. 9:e2000353.

Dimitrijević, M., NevenaArsenović-Ranin, Kosec, D., Bufan, B., Nacka-Aleksić, M., Pilipović, I., et al. (2020). Sex diferences in Tf cell help to B cells contribute to sexual dimorphism in severity of rat collagen-induced arthritis. Sci. Rep. 10:1214.

Dodge, G. R., and Poole, A. R. (1989). Immunohistochemical detection and immunochemical analysis of type II collagen degradation in human normal, rheumatoid, and osteoarthritic articular cartilages and in explants of bovine articular cartilage cultured with interleukin 1. J. Clin. Invest. 83, 647-661. doi: $10.1172 /$ jci113929

Drury, J. L., and Mooney, D. J. (2003). Hydrogels for tissue engineering: scaffold design variables and applications. Biomaterials 24, 4337-4351. doi: 10.1016/ s0142-9612(03)00340-5

Dziki, J. L., Wang, D. S., Pineda, C., Sicari, B. M., Rausch, T., and Badylak, S. F. (2017). Solubilized extracellular matrix bioscaffolds derived from diverse source tissues differentially influence macrophage phenotype. J. Biomed. Mater. Res. A 105, 138-147. doi: 10.1002/jbm.a.35894

Eglin, D., and Alini, M. (2008). Degradable polymeric materials for osteosynthesis: tutorial. Eur. Cells Mater. 16, 80-91. doi: 10.22203/ecm.v016a09

Ekdahl, K. N., Lambris, J. D., Elwing, H., Elwing, H., Nilsson, P. H., Teramura, Y., et al. (2012). Innate immunity activation on biomaterial surfaces: a mechanistic model and coping strategies. Adv. Drug Deliv. Rev. 63, 1042-1050. doi: 10.1016/ j.addr.2011.06.012

Elder, B. D., Kim, D. H., and Athanasiou, K. A. (2010). Developing an articular cartilage decellularization process toward facet Joint cartilage replacement. Neurosurgery 66, 722-727. doi: 10.1227/01.neu.0000367616.49291.9f

English, K. (2013). Mechanisms of mesenchymal stromal cell immunomodulation. Immunol. Cell Biol. 91, 19-26. doi: 10.1038/icb.2012.56

Evans-Nguyen, K. M., Fuierer, R. R., Fitchett, B. D., Tolles, L. R., Conboy, J. C., and Schoenfisch, M. H. (2006). Changes in adsorbed fibrinogen upon conversion to fibrin. Langmuir 22, 5115-5121. doi: 10.1021/la053070y 
Fahy, N., de-Vries-van-Melle, M. L., Lehmann, J., Wei, W., Grotenhuis, N., Farrell, E., et al. (2014). Human osteoarthritic synovium impacts chondrogenic differentiation of mesenchymal stem cells via macrophage polarisation state. Osteoarthritis Cartilage 22, 1167-1175. doi: 10.1016/j.joca.2014.05.021

Feng, X., Xu, P., Shen, T., Zhang, Y., Ye, J., and Gao, C. (2020). Influence of pore architectures of silk fibroin/collagen composite scaffolds on the regeneration of osteochondral defects in vivo. J. Mater. Chem. B 8, 391-405. doi: 10.1039/ c9tb01558b

Ferrante, C. J., and Leibovich, S. J. (2012). Regulation of macrophage polarization and wound healing. Adv. Wound Care 1, 10-16. doi: 10.1089/wound.2011.0307

Fraitzl, C. R., Egli, R. J., Wingenfeld, C., Ganz, R., Hofstetter, W., and Leunig, M. (2008). Time course of biological activity in fresh murine osteochondral allografts paralleled to the recipient's immune response. J. Invest. Surg. 21, 109-117. doi: 10.1080/08941930802043540

Fujihara, Y., Abe, T., and Hoshi, K. (2020). Controlling the phenotype of macrophages promotes maturation of tissue-engineered cartilage. Tissue Eng. Part A 26, 1005-1013. doi: 10.1089/ten.tea.2019.0190

Gannon, A. R., Nagel, T., Bell, A. P., Avery, N. C., and Kelly, D. J. (2015a). Postnatal changes to the mechanical properties of articular cartilage are driven by the evolution of its collagen network. Eur. Cells Mater. 29, 105-123.

Gannon, A. R., Nagel, T., Bell, A. P., Avery, N. C., and Kelly, D. J. (2015b). The changing role of the superficial region in determining the dynamic compressive properties of articular cartilage during postnatal development. Osteoarthritis Cartilage 23, 975-984. doi: 10.1016/j.joca.2015.02.003

Garg, K., Pullen, N. A., Oskeritzian, C. A., Ryan, J. J., and Bowlin, G. L. (2013). Macrophage functional polarization (M1/M2) in response to varying fiber and pore dimensions of electrospun scaffolds. Biomaterials 34, 4439-4451. doi: 10.1016/j.biomaterials.2013.02.065

Gerber, J. S., and Mosser, D. M. (2001). Reversing lipopolysaccharide toxicity by ligating the macrophage Fc gamma receptors. J. Immunol. 166, 6861-6868. doi: 10.4049/jimmunol.166.11.6861

Ghassemi, T., Saghatoleslami, N., Mahdavi-Shahri, N., Matin, M. M., Gheshlaghi, R., and Moradi, A. (2019). A comparison study of different decellularization treatments on bovine articular cartilage. J. Tissue Eng. Regen. Med. 13, 18611871. doi: $10.1002 /$ term. 2936

Gilbert, T. W., Freund, J. M., and Badylak, S. F. (2009). Quantification of DNA in biologic scaffold materials. J. Surg. Res. 152, 135-139. doi: 10.1016/j.jss.2008.02. 013

Gilpin, A., and Yang, Y. (2017). Decellularization strategies for regenerative medicine: from processing techniques to applications. Biomed Res. Int. 2017:9831534.

Gong, W., Lei, D., Li, S., Huang, P., Qi, Q., Sun, Y., et al. (2016). Hybrid small-diameter vascular grafts: anti-expansion effect of electrospun poly $\varepsilon$ caprolactone on heparin-coated decellularized matrices. Biomaterials 76, 359370. doi: 10.1016/j.biomaterials.2015.10.066

Gong, Y. Y., Xue, J. X., Zhang, W. J., Zhou, G. D., Liu, W., and Cao, Y. (2011). A sandwich model for engineering cartilage with acellular cartilage sheets and chondrocytes. Biomaterials 32, 2265-2273. doi: 10.1016/j.biomaterials.2010.11. 078

Göpferich, A. (1996). Mechanisms of polymer degradation and erosion. Biomaterials 17, 103-114. doi: 10.1016/0142-9612(96)85755-3

Griffin, M., Ibrahim, A., Seifalian, A., Butler, P., Kalaskar, D., and Ferretti, P. (2017). Chemical group-dependent plasma polymerisation preferentially directs adipose stem cell differentiation towards osteogenic or chondrogenic lineages. Acta Biomater. 50, 450-461. doi: 10.1016/j.actbio.2016.12.016

Grinberg, S., Hasko, G., Wu, D., and Leibovich, S. J. (2009). Suppression of PLCb2 by endotoxin plays a role in the adenosine A2A receptor-mediated switch of macrophages from an inflammatory to an angiogenic phenotype. Am. J. Pathol. 175, 2439-2453. doi: 10.2353/ajpath.2009.090290

Hachim, D., Iftikhar, A., LoPresti, S. T., Nolfi, A. L., Ravichandar, S., Skillen, C. D., et al. (2019). Distinct release strategies are required to modulate macrophage phenotype in young versus aged animals. J. Control. Release 305, 65-74. doi: 10.1016/j.jconrel.2019.05.020

Han, L., Xu, J., Lu, X., Gan, D., Wang, H., Wang, K., et al. (2017). Biohybrid methacrylated gelatin/polyacrylamide hydrogels for cartilage repair. J. Mater. Chem. B 5, 731-741. doi: 10.1039/c6tb02348g

He, C., Yang, Z., Jin, Y., Qi, X., Chu, J., and Deng, X. (2018). ADM scaffolds generate a pro-regenerative microenvironment during full-thickness cutaneous wound healing through M2 macrophage polarization via Lamtor1. Front. Physiol. 9:657. doi: 10.3389/fphys.2018.00657

Hemmi, H., Takeuchi, O., Kawai, T., Kaisho, T., Sato, S., Sanjo, H., et al. (2000). A toll-like receptor recognizes bacterial DNA. Nature 408, 740-745. doi: 10.1038/ 35047123

Heuberger, M., Drobek, T., and Spencer, N. D. (2005). Interaction forces and morphology of a protein-resistant poly(ethylene glycol) layer. Biophys. J. 88, 495-504. doi: 10.1529/biophysj.104.045443

Hirsh, S. L., McKenzie, D. R., Nosworthy, N. J., Denman, J. A., Sezerman, O. U., and Bilek, M. M. M. (2013). The Vroman effect: competitive protein exchange with dynamic multilayer protein aggregates. Colloids Surf B Biointerfaces 103, 395-404. doi: 10.1016/j.colsurfb.2012.10.039

Horbett, T. A. (2018). Fibrinogen adsorption to biomaterials. J. Biomed. Mater. Res. A 106, 2777-2788. doi: 10.1002/jbm.a.36460

Hotchkiss, K. M., Clark, N. M., and Olivares-Navarrete, R. (2018). Macrophage response to hydrophilic biomaterials regulates MSC recruitment and thelper cell populations. Biomaterials 182, 202-215. doi: 10.1016/j.biomaterials.2018. 08.029

Hu, W. J., Eaton, J. W., and Tang, L. (2001). Molecular basis of biomaterialmediated foreign body reactions. Blood 98, 1231-1238. doi: 10.1182/blood.v98. 4.1231

Huang, Y., Seitz, D., König, F., Müller, P. E., Jansson, V., and Klar, R. M. (2019). Induction of articular chondrogenesis by chitosan/hyaluronic-acidbased biomimetic matrices using human adipose-derived stem cells. Int. J. Mol. Sci. 20:4487. doi: 10.3390/ijms20184487

Huber, E., Pobloth, A.-M., Bormann, N., Kolarczik, N., Schmidt-Bleek, K., Schell, H., et al. (2017). DBM as a carrier for BMP-2: burst release combined with long term binding and osteoinductive activity evaluated in vitro and in vivo. Tissue Eng. Part A. 23, 1321-1330. doi: 10.1089/ten.tea.2017.0005

Huleihel, L., Dziki, J. L., Bartolacci, J. G., Rausch, T., Scarritt, M. E., Cramera, M. C., et al. (2017). Macrophage phenotype in response to ECM bioscaffolds. Semin. Immunol. 29, 2-13. doi: 10.1016/j.smim.2017.04.004

Hume, D. A. (2015). The many alternative faces of macrophage activation. Front. Immunol. 6:370. doi: 10.3389/fimmu.2015.00370

Jabari, F., Hesaraki, S., and Houshmand, B. (2019). The physical, mechanical, and biological properties of silk fibroin/chitosan/reduced graphene oxide composite membranes for guided bone regeneration. J. Biomater. Sci. Polym. Ed. 30, 1779-1802. doi: 10.1080/09205063.2019.1666235

Janeway, C. A. (1989). Approaching the asymptote? evolution and revolution in immunology. Cold Spring Harb. Symp. Quant. Biol. 54, 1-13. doi: 10.1101/sqb. 1989.054.01.003

Jeevithan, E., Jingyi, Z., Wang, N., He, L., Bao, B., and Wu, W. (2015). Physicochemical, antioxidant and intestinal absorption properties of whale shark typeII collagen based on its solubility with acid and pepsin. Process Biochem. 50, 463-472. doi: 10.1016/j.procbio.2014.11.015

Jiang, J., Li, Z., Wang, H., Wang, Y., Carlson, M. A., Teusink, M. J., et al. (2016). Expanded 3D nanofiber scaffolds: cell penetration, neovascularization, and host response. Adv. Healthc. Mater. 5, 2993-3003. doi: 10.1002/adhm.201600808

Jin, S.-S., He, D.-Q., Luo, D., Wang, Y., Yu, M., Guan, B., et al. (2019). A biomimetic hierarchical nanointerface orchestrates macrophage polarization and mesenchymal stem cell recruitment to promote endogenous bone regeneration. ACS Nano 13, 6581-6595. doi: 10.1021/acsnano.9b00489

Jones, J. A., Chang, D. T., Meyerson, H., Colton, E., Kwon, I. K., Matsuda, T., et al. (2007). Proteomic analysis and quantification of cytokines and chemokines from biomaterial surface-adherent macrophages and foreign body giant cells. J. Biomed. Mater. Res. A 83, 585-596. doi: 10.1002/jbm.a.31221

Julier, Z., Park, A. J., Briquez, P. S., and Martino, M. M. (2017). Promoting tissue regeneration by modulating the immune system. Acta Biomater. 53, 13-28. doi: 10.1016/j.actbio.2017.01.056

Junge, K., Binnebösel, M., Trotha, K. T. V., Rosch, R., Klinge, U., Neumann, U. P., et al. (2012). Mesh biocompatibility: effects of cellular inflammation and tissue remodelling. Langenbecks Arch. Surg. 397, 255-270. doi: 10.1007/s00423-0110780-0

Kamath, S., Bhattacharyya, D., Padukudru, C., Timmons, R. B., and Tang, L. (2008). Surface chemistry influences implant-mediated host tissue responses. J. Biomed. Mater. Res. A 86, 617-626. doi: 10.1002/jbm.a.31649

Karayel, E., Bürckstümmer, T., Bilban, M., Dürnberger, G., Weitzer, S., Martinez, J., et al. (2009). The TLR-independent DNA recognition pathway in murine 
macrophages: ligand features and molecular signature. Eur. J. Immunol. 39, 1929-1936. doi: 10.1002/eji.200939344

Kawane, K., Fukuyama, H., Yoshida, H., Nagase, H., Ohsawa, Y., Uchiyama, Y., et al. (2003). Impaired thymic development in mouse embryos deficient in apoptotic DNA degradation. Nat. Immunol. 4, 138-144. doi: 10.1038/ni881

Kawane, K., Ohtani, M., Miwa, K., Kizawa, T., Kanbara, Y., Yoshioka, Y., et al. (2006). Chronic polyarthritis caused by mammalian DNA that escapes from degradation in macrophages. Nature 443, 998-1002. doi: 10.1038/nature05245

Keane, A. N. J., Londono, R., Turner, N. J., and Badylak, S. F. (2012). Consequences of ineffective decellularization of biologic scaffolds on the host response. Biomaterials 33, 1771-1781. doi: 10.1016/j.biomaterials.2011.10.054

Keane, T. J., and Badylak, S. F. (2015). The host response to allogeneic and xenogeneic biological scaffold materials. J. Tissue Eng. Regen. Med. 9, 504-511. doi: $10.1002 /$ term. 1874

Keselowsky, B. G., Collard, D. M., and Garcńı a, A. J. (2004). Surface chemistry modulates focal adhesion composition and signaling through changes in integrin binding. Biomaterials 25, 5947-5954. doi: 10.1016/j.biomaterials.2004. 01.062

Kim, H. J., Han, M. A., Shin, J. Y., Jeon, J. H., Lee, S. J., Yoon, M. Y., et al. (2019). Intra-articular delivery of synovium-resident mesenchymal stem cells via BMP7-loaded fibrous PLGA scaffolds for cartilage repair. J. Control. Release 302, 169-180. doi: 10.1016/j.jconrel.2019.04.002

Kim, J. (2017). Mathematical modeling approaches to describe the dynamics of protein adsorption at solid interfaces. Colloids Surf B Biointerfaces 162, 370-379. doi: 10.1016/j.colsurfb.2017.12.006

Kimura, T., Nada, S., Takegahara, N., Okuno, T., Nojima, S., Kang, S., et al. (2016). Polarization of M2 macrophages requires Lamtorl that integrates cytokine and amino-acid signals. Nat. Commun. 7:13130.

Kock, N. B., Smolders, J. M. H., Susante, J. L. C. V., Buma, P., Kampen, A. V., and Verdonschot, N. (2008). A cadaveric analysis of contact stress restoration after osteochondral transplantation of a cylindrical cartilage defect. Knee. Surg. Sports Traumatol. Arthrosc. 16, 461-468. doi: 10.1007/s00167-008-0494-1

Kundu, B., Rajkhowa, R., Kundu, S. C., and Wang, X. (2013). Silk fibroin biomaterials for tissue regenerations. Adv. Drug Deliv. Rev. 65, 457-470. doi: 10.1016/j.addr.2012.09.043

Lan, M. A., Gersbach, C. A., Michael, K. E., Keselowsky, B. G., and García, A. J. (2005). Myoblast proliferation and differentiation on fibronectin-coated self assembled monolayers presenting different surface chemistries. Biomaterials 26, 4523-4531. doi: 10.1016/j.biomaterials.2004.11.028

Lendlein, A., and Langer, R. (2002). Biomedical applications biodegradable. elastic shape-memory polymers for potential. Science 296, 1673-1676. doi: 10.1126/ science. 1066102

Li, A., Wei, Y., Hung, C., and Vunjak-Novakovic, G. (2018). Chondrogenic properties of collagen type XI, a component of cartilage extracellular matrix. Biomaterials 173, 47-57. doi: 10.1016/j.biomaterials.2018.05.004

Li, M., Wei, F., Yin, X., Xiao, L., Yang, L., Su, J., et al. (2020). Synergistic regulation of osteoimmune microenvironment by IL- 4 and RGD to accelerate osteogenesis. Mater. Sci. Eng. C Mater. Biol. Appl. 109:110508. doi: 10.1016/j. msec.2019.110508

Li, S., Tallia, F., Mohammed, A. A., Stevens, M. M., and Jones, J. R. (2020). Scaffold channel size influences stem cell differentiation pathway in 3-D printed silica hybrid scaffolds for cartilage regeneration. Biomater. Sci. 8, 4458-4466. doi: $10.1039 / \mathrm{c} 9 \mathrm{bm} 01829 \mathrm{~h}$

Li, X., Guo, W., Zha, K., Jing, X., Wang, M., Zhang, Y., et al. (2019a). Enrichment of CD146+ Adipose-Derived stem cells in combination with articular cartilage extracellular matrix scaffold promotes cartilage regeneration. Theranostics 9 , 5105-5121. doi: 10.7150/thno.33904

Li, Y., Liu, Y., Xun, X., Zhang, W., Xu, Y., and Gu, D. (2019b). Three-dimensional porous scaffolds with biomimetic microarchitecture and bioactivity for cartilage tissue engineering. ACS Appl. Mater. Interfaces 11, 36359-36370. doi: 10.1021/ acsami.9b12206

Li, Y., Xu, Y., Liu, Y., Wang, Z., Chen, W., Duan, L., et al. (2019c). Decellularized cartilage matrix scaffolds with laser-machined micropores for cartilage regeneration and articular cartilage repair. Mater. Sci. Eng. C Biomim. Supramol. Syst. 105:110139. doi: 10.1016/j.msec.2019.110139

Lin, T.-H., Wang, H.-C., Cheng, W.-H., Hsu, H.-C., and Yeh, M.-L. (2019). Osteochondral tissue regeneration using a tyramine-modified bilayered PLGA scaffold combined with articular chondrocytes in a porcine model. Int. J. Mol. Sci. 20:326. doi: 10.3390/ijms20020326
Lin, X., Wang, W., Zhang, W., Zhang, Z., Zhou, G., Cao, Y., et al. (2017). Hyaluronic acid coating enhances biocompatibility of nonwoven PGA scaffold and cartilage formation. Tissue Eng. Part C Methods 23, 86-97. doi: 10.1089/ ten.tec.2016.0373

Lin, Y. K., and Liu, D. C. (2006). Effects of pepsin digestion at different temperatures and times on properties of telopeptide-poor collagen from bird feet. Food Chem. 94, 621-625. doi: 10.1016/j.foodchem.2004.12.007

Linares, J., Fernández, A. B., Feito, M. J., Matesanz, M. C., Sánchez-Salcedo, S., Arcos, D., et al. (2016). Effects of nanocrystalline hydroxyapatites on macrophage polarization. J. Mater. Chem. B 4, 1951-1959. doi: 10.1039/ c6tb00014b

Lindberg, G., Longoni, A., Lim, K., Rosenberg, A., Hooper, G., Gawlitta, D., et al. (2019). Intact vitreous humor as a potential extracellular matrix hydrogel for cartilage tissue engineering applications. Acta Biomater. 85, 117-130. doi: 10.1016/j.actbio.2018.12.022

Liu, D., Nikoo, M., Boran, G., Zhou, P., and Regenstein, J. M. (2015). Collagen and gelatin. Annu. Rev. Food Sci. Technol. 6, 527-557.

Lohfeld, S., Cahill, S., Doyle, H., and McHugh, P. E. (2015). Improving the finite element model accuracy of tissue engineering scaffolds produced by selective laser sintering. J. Mater. Sci. Mater. Med. 26, 1-12.

Londono, R., and Badylak, S. F. (2015). Biologic scaffolds for regenerative medicine: mechanisms of in vivo remodeling. Ann. Biomed. Eng. 43, 577-592. doi: 10. 1007/s10439-014-1103-8

Lopa, S., Leijs, M. J. C., Moretti, M., Lubberts, E., van Osch, G. J., and BastiaansenJenniskens, Y. M. (2015). Arthritic and non-arthritic synovial fluids modulate IL10 and IL1RA gene expression in differentially activated primary human monocytes. Osteoarthritis Cartilage 23, 1853-1857. doi: 10.1016/j.joca.2015.06. 003

Lu, D. R., and Park, K. (1991). Effect of surface hydrophobicity on the conformational changes of adsorbed fibrinogen. J. Colloid Interface Sci. 144, 271-281. doi: 10.1016/0021-9797(91)90258-a

Lu, Z., Liu, S., Le, Y., Qin, Z., He, M., Xu, F., et al. (2019). An injectable collagengenipin-carbon dot hydrogel combined with photodynamic therapy to enhance chondrogenesis. Biomaterials 2018:119190. doi: 10.1016/j.biomaterials.2019. 05.001

Lukanina, K. I., Grigoriev, T. E., Krasheninnikov, S. V., Mamagulashvilli, V. G., Kamyshinsky, R. A., and Chvalun, S. N. (2018). Multi-hierarchical tissueengineering ECM-like scaffolds based on cellulose acetate with collagen and chitosan fillers. Carbohydr. Polym. 191, 119-126. doi: 10.1016/j.carbpol.2018. 02.061

Luo, L., Eswaramoorthy, R., Mulhall, K. J., and Kelly, D. J. (2015). Decellularization of porcine articular cartilage explants and their subsequent repopulation with human chondroprogenitor cells. J. Mech. Behav. Biomed. Mater. 55, 21-31. doi: 10.1016/j.jmbbm.2015.10.002

Ma, Q.-L., Zhao, L.-Z., Liu, R.-R., Jin, B.-Q., Song, W., Wang, Y., et al. (2014). Improved implant osseointegration of a nanostructured titanium surface via mediation of macrophage polarization. Biomaterials 35, 9853-9867. doi: 10. 1016/j.biomaterials.2014.08.025

Madden, L. R., Mortisen, D. J., Sussman, E. M., Dupras, S. K., Fugate, J. A., Cuy, J. L., et al. (2010). Proangiogenic scaffolds as functional templates for cardiac tissue engineering. Proc. Natl. Acad. Sci. U S A. 107, 15211-15216. doi: 10.1073/pnas.1006442107

Mainil-Varlet, P., Rieser, F., Grogan, S., Mueller, W., Saager, C., and Jakob, R. P. (2001). Articular cartilage repair using a tissue-engineered cartilage-like implant: an animal study. Osteoarthritis Cartilage 9(Suppl. A), S6-S15.

Makris, E. A., Gomoll, A. H., Malizos, K. N., Hu, J. C., and Athanasiou, K. A. (2015). Repair and tissue engineering techniques for articular cartilage. Nat. Rev. Rheumatol. 11, 21-34. doi: 10.1038/nrrheum.2014.157

Manferdini, C., Paolella, F., Gabusi, E., Gambari, L., Piacentini, A., Filardo, G., et al. (2017). Adipose stromal cells mediated switching of the pro-inflammatory profile of M1-like macrophages is facilitated by PGE2: in vitro evaluation. Osteoarthritis Cartilage 25, 1161-1171. doi: 10.1016/j.joca.2017.01.011

Manivel, V. A., Sohrabian, A., Wick, M. C., Mullazehi, M., Håkansson, L. D., and Rönnelid, J. (2015). Anti-type II collagen immune complex-induced granulocyte reactivity is associated with joint erosions in RA patients with anti-collagen antibodies. Arthritis Res. Ther. 17:8. doi: 10.1186/s13075-0150523-7

Martinez, F. O., and Gordon, S. (2014). The M1 and M2 paradigm of macrophage activation: time for reassessment. F1000Prime Rep. 6:13. 
Matzinger, P. (1994). Tolerance, danger, and the extended family. Annu. Rev. Immunol. 12, 991-1045. doi: 10.1146/annurev.iy.12.040194.005015

McCarthy, H. S., Richardson, J. B., Parker, J. C. E., and Roberts, S. (2016). Evaluating joint morbidity after chondral harvest for Autologous Chondrocyte Implantation (ACI): a study of ACI-Treated ankles and hips with a knee chondral harvest. Cartilage 7, 7-15. doi: 10.1177/1947603515607963

McNally, A. K., and Anderson, J. M. (2002). $\beta 1$ and $\beta 2$ integrins mediate adhesion during macrophage fusion and multinucleated foreign body giant cell formation. Am. J. Pathol. 160, 621-630. doi: 10.1016/s0002-9440(10)64882-1

Meng, F. W., Slivka, P. F., Dearth, C. L., and Badylak, S. F. (2015). Solubilized extracellular matrix from brain and urinary bladder elicits distinct functional and phenotypic responses in macrophages. Biomaterials 46, 131-140. doi: 10.1016/j.biomaterials.2014.12.044

Milan, P. B., Pazouki, A., Joghataei, M. T., Mozafari, M., Amini, N., Kargozar, S., et al. (2019). Decellularization and preservation of human skin: a platform for tissue engineering and reconstructive surgery. Methods 171, 62-67. doi: 10.1016/j.ymeth.2019.07.005

Miller, E. J. (1971). Isolation and characterization of a collagen from chick cartilage containing three identical alpha chains. Biochemistry 10, 1652-1659. doi: 10. 1021/bi00785a024

Milleret, V., Buzzi, S., Gehrig, P., Ziogas, A., Grossmann, J., Schilcher, K., et al. (2015). Protein adsorption steers blood contact activation on engineered cobalt chromium alloy oxide layers. Acta Biomater. 24, 343-351. doi: 10.1016/j.actbio. 2015.06.020

Mills, C. D., Kincaid, K., Alt, J. M., Heilman, M. J., and Hill, A. M. (2000). M1/M-2 macrophages and the Th1/Th2 Paradigm. J. Immunol. 164, 6166-6173. doi: 10.4049/jimmunol.164.12.6166

Mimura, K. K. O., Moraes, A. R., Miranda, A. C., Greco, R., Ansari, T., Sibbons, P., et al. (2016). Mechanisms underlying heterologous skin scaffold-mediated tissue remodeling. Sci. Rep. 6:35074.

Mosser, D. M. (2003). The many faces of macrophage activation. J. Leukoc. Biol. 73, 209-212. doi: 10.1189/jlb.0602325

Mosser, D. M., and Edwards, J. P. (2008). Exploring the full spectrum of macrophage activation. Nat. Rev. Immunol. 8, 958-969. doi: 10.1038/nri2448

Moyano, D. F., Goldsmith, M., Solfiell, D. J., Landesman-Milo, D., Miranda, O. R., Peer, D., et al. (2012). Nanoparticle hydrophobicity dictates immune response. J. Am. Chem. Soc. 134, 3965-3967. doi: 10.1021/ja2108905

Murray, P. J., Allen, J. E., Biswas, S. K., Fisher, E. A., Gilroy, D. W., Goerdt, S., et al. (2014). Macrophage activation and polarization: nomenclature and experimental guidelines. Immunity 41, 14-20. doi: 10.1016/j.immuni.2014.06. 008

Nagata, S., Hanayama, R., and Kawane, K. (2010). Autoimmunity and the clearance of dead cells. Cell 140, 619-630. doi: 10.1016/j.cell.2010.02.014

Nagubothu, S. R., Sugars, R. V., Tudzarovski, N., Andrén, A. T., Bottai, M., Davies, L. C., et al. (2020). Mesenchymal stromal cells modulate tissue repair responses within the injured vocal fold. Laryngoscope 130, E21-E29.

Nair, A., Zou, L., Bhattacharyya, D., Timmons, R. B., and Tang, L. (2008). Species and density of implant surface chemistry affect the extent of foreign body reactions. Langmuir 24, 2015-2024. doi: 10.1021/la7025973

Nasiri, B., and Mashayekhan, S. (2017). Fabrication of porous scaffolds with decellularized cartilage matrix for tissue engineering application. Biologicals 48, 39-46. doi: 10.1016/j.biologicals.2017.05.008

Nathani, A., Gold, G. E., Monu, U., Hargreaves, B., Finlay, A. K., Rubin, E. B., et al. (2019). Does injection of hyaluronic acid protect against early cartilage injury seen after marathon running? a randomized controlled trial utilizing high-field magnetic resonance imaging. Am. J. Sports Med. 47, 3414-3422. doi: $10.1177 / 0363546519879138$

Nehrer, S., Breinan, H. A., Ramappa, A., Hsu, H.-P., Minas, T., Shortkrof, S., et al. (1998). Chondrocyteseeded collagen matrices implanted in a chondral defect in a canine model. Biomaterials 19, 2313-2328. doi: 10.1016/s0142-9612(98) 00143-4

Nie, X., Chuah, Y. J., Zhu, W., He, P., Peck, Y., and Wang, D.-A. (2020). Decellularized tissue engineered hyaline cartilage graft for articular artilage repair. Biomaterials 235:119821. doi: 10.1016/j.biomaterials.2020.119821

Ohto, U., Shibata, T., Tanji, H., Ishida, H., Krayukhina, E., Uchiyama, S., et al. (2015). Structural basis of CpG and inhibitory DNA recognition by Toll-like receptor 9. Nature 520, 702-705. doi: 10.1038/nature14138
Orenstein, S. B., Saberski, E. R., Klueh, U., Kreutzer, D. L., and Novitsky, Y. W. (2010). Effects of mast cell modulation on early host response to implanted synthetic meshes. Hernia 14, 511-516. doi: 10.1007/s10029-010-0680-1

Palmer, J. A., Abberton, K. M., Mitchell, G. M., and Mitchell, G. M. (2014). Macrophage phenotype in response to implanted synthetic scaffolds: an immunohistochemical study in the rat. Cells Tissues Organs 199, 169-183. doi: $10.1159 / 000363693$

Pape, A. C. H., Ippel, B. D., and Dankers, P. Y. W. (2017). Cell and protein fouling properties of polymeric mixtures containing supramolecular poly(ethylene glycol) additives. Langmuir 33, 4076-4082. doi: 10.1021/acs.langmuir.7b00467

Park, K.-S., Kim, B.-J., Lih, E., Park, W., Lee, S.-H., Joung, Y. K., et al. (2018). Versatile effects of magnesium hydroxide nanoparticles in PLGA scaffoldmediated chondrogenesis. Acta Biomater. 73, 204-216. doi: 10.1016/j.actbio. 2018.04.022

Pati, F., Jang, J., Ha, D.-H., Kim, S. W., Rhie, J.-W., Shim, J.-H., et al. (2014). Printing three-dimensional tissue analogues with decellularized extracellular matrix bioink. Nat. Commun. 5:3935.

Pattappa, G., Zellner, J., Johnstone, B., Docheva, D., and Angele, P. (2019). Cells under pressure - the relationship between hydrostatic pressure and mesenchymal stem cell chondrogenesis. Eur. Cells Mater. 37, 360-381. doi: 10.22203/ecm.v037a22

Peppas, N. A., and Langer, R. (1994). New challenges in biomaterials. Science 263, 1715-1720. doi: 10.1126/science. 8134835

Pérez-Silos, V., Moncada-Saucedo, N. K., Peña-Martínez, V., Lara-Arias, J., Marino-Martínez, I. A., and Camacho, A. (2019). A cellularized biphasic implant based on a bioactive silk fibroin promotes integration and tissue organization during osteochondral defect repair in a porcine model. Int. J. Mol. Sci. 20:5145. doi: 10.3390/ijms20205145

Pestka, J. M., Bode, G., Salzmann, G., Südkamp, N. P., and Niemeyer, P. (2012). Clinical outcome of autologous chondrocyte implantation for failed microfracture treatment of full-thickness cartilage defects of the knee joint. Am. J. Sports Med. 40, 325-331. doi: 10.1177/0363546511425651

Pustlauk, W., Paul, B., Gelinsky, M., and Bernhardt, A. (2016). Jellyfish collagen and alginate: combined marine materials for superior chondrogenesis of hMSC. Mater. Sci. Eng. C Biomim. Supramol. Syst. 64, 190-198. doi: 10.1016/j.msec. 2016.03.081

Qiu, X., Liu, S., Zhang, H., Zhu, B., Su, Y., Zheng, C., et al. (2018). Mesenchymal stem cells and extracellular matrix scaffold promote muscle regeneration by synergistically regulating macrophage polarization toward the M2 phenotype. Stem Cell Res. Ther. 9:88.

Raimondo, T. M., and Mooney, D. J. (2018). Functional muscle recovery with nanoparticle-directed M2 macrophage polarization in mice. Proc. Natl. Acad. Sci. U S A. 115, 10648-10653. doi: 10.1073/pnas. 1806908115

Rezwan, K., Chen, Q. Z., Blaker, J. J., and Boccaccini, A. R. (2006). Biodegradable and bioactive porous polymer/inorganic composite scaffolds for bone tissue engineering. Biomaterials 27, 3413-3431. doi: 10.1016/j.biomaterials.2006.01. 039

Rostam, H. M., Singh, S., Salazar, F., Magennis, P., Hook, A., Singh, T., et al. (2016). The impact of surface chemistry modification on macrophage polarisation. Semin. Immunol. 221, 1237-1246. doi: 10.1016/j.imbio.2016.06.010

Roth, S. P., Glauche, S. M., Plenge, A., Erbe, I., Heller, S., and Burk, J. (2017). Automated freeze-thaw cycles for decellularization of tendon tissue - a pilot study. BMC Biotechnol. 17:13. doi: 10.1186/s12896-0170329-6

Ryszer, T. (2015). Understanding the mysterious M2 macrophage through activation markers and effector mechanisms. Med. Inflamm. 2015:816460.

Sadtler, K., Wolf, M. T., Ganguly, S., Moad, C. A., Chung, L., Majumdar, S., et al. (2019). Divergent immune responses to synthetic and biological scaffolds. Biomaterials 192, 405-415. doi: 10.1016/j.biomaterials.2018.11.002

Salonius, E., Kontturi, L., Laitinen, A., Haaparanta, A. M., Korhonen, M., Nystedt, J., et al. (2020). Chondrogenic differentiation of human bone marrow-derived mesenchymal stromal cells in a three-dimensional environment. J. Cell. Physiol. 235, 3497-3507. doi: 10.1002/jcp.29238

Scarneo, S. A., Eibschutz, L. S., Bendele, P. J., Yang, K. W., Totzke, J., Hughes, P., et al. (2019). Pharmacological inhibition of TAK1, with the selective inhibitor takinib, alleviates clinical manifestation of arthritis in CIA mice. Arthritis Res. Ther. 21:292. 
Schipani, R., Nolan, D. R., Lally, C., and Kelly, D. J. (2020). Integrating finite element modelling and 3D printing to engineer biomimetic polymeric scaffolds for tissue engineering. Connect. Tissue Res. 61, 174-189. doi: 10.1080/03008207. 2019.1656720

Schneider, C., Lehmann, J., van-Osch, G. J. V. M., Hildner, F., Teuschl, A., Monforte, X., et al. (2016). Systematic comparison of protocols for the preparation of human articular cartilage for use as scaffold material in cartilage tissue engineering. Tissue Eng. Part C Methods 22, 1095-1107. doi: 10.1089/ten. tec.2016.0380

Schwarz, S., Koerber, L., Elsaesser, A. F., Goldberg-Bockhorn, E., Seitz, A. M., Dürselen, L., et al. (2012). Decellularized cartilage matrix as a novel biomatrix for cartilage tissue-engineering applications. Tissue Eng. Part A 18, 2195-2209. doi: 10.1089/ten.tea.2011.0705

Seong, S.-Y., and Matzinger, P. (2004). Hydrophobicity: an ancient damageassociated molecular pattern that initiates innate immune responses. Nat. Rev. Immunol. 4, 469-478. doi: 10.1038/nri1372

Shahbaz, S. K., Foroughi, F., Soltaninezhad, E., Jamialahmadi, T., Penson, P. E., and Sahebkar, A. (2020). Application of PLGA nano/microparticle delivery systems for immunomodulation and prevention of allotransplant rejection. Expert Opin. Drug Delivery 17, 767-780. doi: 10.1080/17425247.2020.1748006

Shamloo, A., and Sarmadi, M. (2016). Investigation of the adhesive characteristics of polymer-protein systems through molecular dynamics simulation and their relation to cell adhesion and proliferation. Integr. Biol. (Camb) 8, 1276-1295. doi: 10.1039/c6ib00159a

Shayegan, M., Altindal, T., Kiefl, E., and Forde, N. R. (2016). Intact telopeptides enhance interactions between collagens. Biophys. J. 111, 2404-2416. doi: 10. 1016/j.bpj.2016.10.039

Shen, W., Berning, K., Tang, S. W., and Lam, Y. W. (2020). Rapid and detergentfree decellularization of cartilage. Tissue Eng. Part C Methods 26, 201-206. doi: $10.1089 /$ ten.tec.2020.0008

Shetty, A. A., Kim, S. J., Bilagi, P., and Stelzeneder, D. (2013). Autologous collageninduced chondrogenesis: single-stage arthroscopic cartilage repair technique. Orthopedics 36, e648-e652.

Sicari, B. M., Dziki, J. L., Siu, B. F., Medberry, C. J., Dearth, C. L., and Badylak, S. F. (2014). The promotion of a constructive macrophage phenotype by solubilized extracellular matrix. Biomaterials 35, 8605-8612. doi: 10.1016/j.biomaterials. 2014.06.060

Silva, J. C., Udangawa, R. N., Chen, J., Mancinelli, C. D., Garrudo, F. F. F., Mikael, P. E., et al. (2020). Kartogenin-loaded coaxial PGS/PCL aligned nanofibers for cartilage tissue engineering. Mater. Sci. Eng. C Biomim. Supramol. Syst. 107:110291. doi: 10.1016/j.msec.2019.110291

Singh, Y. P., Bandyopadhyay, A., and Mandal, B. B. (2019). 3D bioprinting using cross-linker free silkgelatin bioink for cartilage tissue engineering. ACS Appl. Mater. Interfaces 11, 33684-33696. doi: 10.1021/acsami.9b11644

Sirlin, C. B., Brossmann, J., Boutin, R. D., Pathria, M. N., Convery, F. R., Bugbee, W., et al. (2001). Shell osteochondral allografts of the knee: comparison of MR imaging findings and immunologic responses. Radiology 219, 35-43. doi: 10.1148/radiology.219.1.r01ap0435

Slivka, P. F., Dearth, C. L., Keane, T. J., Meng, F. W., Medberry, C. J., Riggio, R. T., et al. (2014). Fractionation of an ECM hydrogel into structural and soluble components reveals distinctive roles in regulating macrophage behavior. Biomater. Sci. 2, 1521-1534. doi: 10.1039/c4bm00189c

Smith, B., Sigal, I. R., and Grande, D. A. (2015). Immunology and cartilage regeneration. Immunome Res. 63, 181-186. doi: 10.1007/s12026-015-8720-7

Solheim, E., Hegna, J., Strand, T., Harlem, T., and Inderhaug, E. (2018). Randomized study of long-term(15-17 Years)outcome after microfracture versus mosaicplasty in knee articular cartilage defects. Am. J. Sports Med. 46, 826-831. doi: 10.1177/0363546517745281

Sophia-Fox, A. J., Bedi, A., and Rodeo, S. A. (2009). The basic science of articular cartilage: structure, composition, and function. Sports Health 1, 461-468. doi: $10.1177 / 1941738109350438$

Sperlinga, C., Schweissa, R. B., Strellera, U., and Werner, C. (2005). In vitro hemocompatibility of self-assembled monolayers displaying various functional groups. Biomaterials 26, 6547-6557. doi: 10.1016/j.biomaterials.2005.04.042

Spiller, K. L., Anfang, R. R., Spiller, K. J., Ng, J., Nakazawa, K. R., Daulton, J. W., et al. (2014). The role of macrophage phenotype in vascularization of tissue engineering scaffolds. Biomaterials 35, 4477-4488. doi: 10.1016/j.biomaterials. 2014.02 .012
Spiller, K. L., Nassiri, S., Witherel, C. E., Anfang, R. R., Ng, J., Nakazawa, K. R., et al. (2015). Vunjak-Novakovic, G., Sequential delivery of immunomodulatory cytokines to facilitate the M1-to-M2 transition of macrophages and enhance vascularization of bone scaffolds. Biomaterials 37, 194-207. doi: 10.1016/j. biomaterials.2014.10.017

Sridharan, R., Cameron, A. R., Kelly, D. J., Kearney, C. J., and O'Brien, F. J. (2015). Biomaterial based modulation of macrophage polarization: a review and suggested design principles. Mater. Today 18, 313-325. doi: 10.1016/j.mattod. 2015.01.019

Stefani, R. M., Lee, A. J., Tan, A. R., Halder, S. S., Hu, Y., Guo, X. E., et al. (2020). Sustained Low-dose dexamethasone delivery via a PLGA microsphereembedded agarose implant for enhanced osteochondral repair. Acta Biomater. 102, 326-340. doi: 10.1016/j.actbio.2019.11.052

Stocco, E., Barbon, S., Dalzoppo, D., Lora, S., Sartore, L., Folin, M., et al. (2014). Tailored PVA/ECM scaffolds for cartilage regeneration. Biomed Res. Int. 2014:762189.

Stratton, S., Shelke, N. B., Hoshino, K., Rudraiah, S., and Rudraiah, S. (2016). Bioactive polymeric scaffolds for tissue engineering. Bioact Mater. 1, 93-108. doi: 10.1016/j.bioactmat.2016.11.001

Sun, X., Yin, H., Wang, Y., Lu, J., Shen, X., Lu, C., et al. (2018). In situ articular cartilage regeneration through endogenous reparative cell homing using a functional bone marrow-specific scaffolding system. ACS Appl. Mater. Interfaces 10, 38715-38728. doi: 10.1021/acsami.8b11687

Sutherland, A. J., Converse, G. L., Hopkins, R. A., and Detamore, M. S. (2015). The bioactivity of cartilage extracellular matrix in articular cartilage regeneration. Adv. Healthc. Mater. 4, 29-39. doi: 10.1002/adhm.201400 165

Tamaddon, M., Burrows, M., Ferreira, S. A., Dazzi, F., Apperley, J. F., Bradshaw, A., et al. (2017). Monomeric, porous type II collagen scaffolds promote chondrogenic differentiation of human bone marrow mesenchymal stem cells in vitro. Sci. Rep. 7:43519.

Tanaka, M., Kawai, S., and Iwasaki, Y. (2017). Well-defined protein immobilization on photo-responsive phosphorylcholine polymer surfaces. J. Biomater. Sci. Polym. Ed. 28, 2021-2033. doi: 10.1080/09205063.2017.1366251

Taraballi, F., Sushnitha, M., Tsao, C., Guillermo, B., Liverani, C., Shi, A., et al. (2018). Biomimetic tissue engineering: tuning the immune and inflammatory response to implantable biomaterials. Adv. Healthc. Mater. 7:1800490. doi: 10.1002/adhm.201800490

Tarique, A. A., Logan, J., Thomas, E., Holt, P. G., Sly, P. D., and Fantino, E. (2015). Phenotypic, functional and plasticity features of classical and alternatively activated human macrophages. Am. J. Respir. Cell Mol. Biol. 53, 676-688. doi: 10.1165/rcmb.2015-0012oc

Thevenot, P., Hu, W., and Tang, L. (2008). Surface chemistry influences implant biocompatibility. Curr. Top. Med. Chem. 8, 270-280. doi: 10.2174/ 156802608783790901

Tiller, J. C., Bonner, G., Pan, L.-C., and Klibanov, A. M. (2001). Improving biomaterial properties of collagen films by chemical modification. Biotechnol. Bioeng. 73, 246-252. doi: 10.1002/bit.1057

Trentham, D. E., Townes, A. S., and Kang, A. H. (1977). Autoimmunity to type II collagen: an experimental model of arthritis. J. Exp. Med. 146, 857-868. doi: 10.1084 /jem.146.3.857

Vainieri, M. L., Lolli, A., Kops, N., D’Atri, D., Eglin, D., Yayon, A., et al. (2020). Evaluation of biomimetic hyaluronic-based hydrogels with enhanced endogenous cell recruitment and cartilage matrix formation. Acta Biomater. 101, 293-303. doi: 10.1016/j.actbio.2019.11.015

Ventura, R. D., Padalhin, A. R., Park, C. M., and Lee, B. T. (2019). Enhanced decellularization technique of porcine dermal ECM for tissue engineering applications. Mater. Sci. Eng. C Biomim. Supramol. Syst. 104:109841. doi: 10. 1016/j.msec.2019.109841

Venugopal, E., Sahanand, K. S., Orthopedic, M., Bhattacharyya, A., and Rajendran, S. (2019). Electrospun PCL nanofibers blended with Wattakaka volubilis active phytochemicals for bone and cartilage tissue engineering. Nanomedicine 21:102044. doi: 10.1016/j.nano.2019.102044

Verreck, F. A. W., Boer, T. D., Langenberg, D. M. L., Hoeve, M. A., Kramer, M., Vaisberg, E., et al. (2004). Human IL-23-producing type 1 macrophages promote but IL-10-producing type 2 macrophages subvert immunity to (myco)bacteria. Proc. Natl. Acad. Sci. U S A. 101, 4560-4565. doi: 10.1073/pnas. 0400983101 
Vollkommer, T., Henningsen, A., Friedrich, R. E., Felthaus, O. H., Eder, F., Morsczeck, C., et al. (2019). Extent of inflammation and foreign body reaction to porous polyethylene in vitro and in vivo. In Vivo 33, 337-347. doi: 10.21873/ invivo. 11479

Wang, C., Brisson, B. K., Terajima, M., Li, Q., Hoxha, K. H., Han, B., et al. (2020a). Type III collagen is a key regulator of the collagen fibrillar structure and biomechanics of articular cartilage and meniscus. Matrix Biol. 8, 47-67. doi: 10.1016/j.matbio.2019.10.001

Wang, C., Yue, H., Huang, W., Lin, X., Xie, X., He, Z., et al. (2020b). Cryogenic $3 \mathrm{D}$ printing of heterogeneous scaffolds with gradient mechanical strengths and spatial delivery of osteogenic peptide/TGF- $\beta 1$ for osteochondral tissue regeneration. Biofabrication 12:025030. doi: 10.1088/1758-5090/ab7ab5

Wang, Z., Li, Z., Li, Z., Wu, B., Liu, Y., and Wu, W. (2018). Cartilaginous extracellular matrix derived from decellularized chondrocyte sheets for the reconstruction of osteochondral defects in rabbits. Acta Biomater. 81, 129-145. doi: 10.1016/j.actbio.2018.10.005

Wasyłeczko, M., Sikorska, W., and Chwojnowski, A. (2020). Review of synthetic and hybrid scaffolds in cartilage tissue engineering. Membranes (Basel) 10, $1-28$.

Waters, M., VandeVord, P., and Dyke, M. V. (2017). Keratin biomaterials augment anti-inflammatory macrophage phenotype in vitro. Acta Biomater. 66, 213-223. doi: 10.1016/j.actbio.2017.10.042

Widuchowski, W., Widuchowski, J., and Trzaska, T. (2007). Articular cartilage defects: study of 25,124 knee arthroscopies. Knee 14, 177-182. doi: 10.1016/ j.knee.2007.02.001

Wiktorowicz, J. E., Chowdhury, I. H., Stafford, S., Choudhuri, S., Dey, N., and Garg, N. J. (2019). Integrated functional analysis of the nuclear proteome of classically and alternatively activated macrophages. Mediators Inflamm. 2019:3481430.

Wilson, C. J., Clegg, R. E., Leavesley, D. I., and Pearcy, M. J. (2005). Mediation of biomaterial-cell interactions by adsorbed proteins: a review. Tissue Eng. 11, 1-18. doi: 10.1089/ten.2005.11.1

Wong, M. L., and Griffiths, L. G. (2014). Immunogenicity in xenogeneic scaffold generation: antigen removal vs. decellularization. Acta Biomater. 10, 18061816. doi: 10.1016/j.actbio.2014.01.028

Wu, Q. Y., Xiong, X. T., Zhang, X. L., Lu, J. Q., Zhang, X. M., Chen, W., et al. (2015). Secondary osteoporosis in collagen-induced arthritis rats. J. Bone Miner. Metab. 34, 500-516. doi: 10.1007/s00774-015-0700-4

Wu, R.-X., He, X.-T., Zhu, J.-H., Yin, Y., Li, X., Liu, X., et al. (2019). Modulating macrophage responses to promote tissue regeneration by changing the formulation of bone extracellular matrix from filler particles to gel bioscaffolds. Mater. Sci. Eng. C Biomim. Supramol. Syst. 101, 330-340. doi: 10.1016/j.msec. 2019.03.107

Wu, R.-X., Ma, C., Liang, Y., Chen, F.-M., and Liu, X. (2020). ECM-mimicking nanofibrous matrix coaxes macrophages toward an anti-inflammatory phenotype: cellular behaviors and transcriptome analysis. Appl. Mater. Today 18:100508. doi: 10.1016/j.apmt.2019.100508

Xia, H., Zhao, D., Zhu, H., Hua, Y., Xiao, K., Xu, Y., et al. (2018). Lyophilized scaffolds fabricated from 3D-printed photocurable natural hydrogel for cartilage regeneration. ACS Appl. Mater. Interfaces 10, 31704-31715. doi: 10. 1021/acsami.8b10926

Xiao, H., Huang, W., Xiong, K., Ruan, S., Yuan, C., Mo, G., et al. (2019). Osteochondral repair using scaffolds with gradient pore sizes constructed with silk fibroin, chitosan, and nano-hydroxyapatite. Int. J. Nanomed. 14, 2011-2027. doi: $10.2147 /$ ijn.s191627

Xu, L. C., and Siedlecki, C. A. (2007). Effects of surface wettability and contact time on protein adhesion to biomaterial surfaces. Biomaterials 28, 3273-3283. doi: 10.1016/j.biomaterials.2007.03.032

Xue, J. X., Gong, Y. Y., Zhou, G. D., Liu, W., Cao, Y. L., and Zhang, W. J. (2012). Chondrogenic differentiation of bone marrow-derived mesenchymal stem cells induced by acellular cartilage sheets. Biomaterials 33, 5832-5840. doi: 10.1016/j.biomaterials.2012.04.054
Yang, D., Lü, X., Hong, Y., Xi, T., and Zhang, D. (2013). The molecular mechanism of mediation of adsorbed serum proteins to endothelial cells adhesion and growth on biomaterials. Biomaterials 34, 5747-5758. doi: 10 . 1016/j.biomaterials.2013.04.028

Yang, Q., Peng, J., Guo, Q., Huang, J., Zhang, L., Yao, J., et al. (2008). A cartilage ECM-derived 3-D porous acellular matrix scaffold for in vivo cartilage tissue engineering with PKH26-labeled chondrogenic bone marrowderived mesenchymal stem cells. Biomaterials 29, 2378-2387. doi: 10.1016/j. biomaterials.2008.01.037

Yang, R., Liao, Y., Wang, L., He, P., Hu, Y., Yuan, D., et al. (2019). Exosomes derived from M2b macrophages attenuate DSS-induced colitis. Front. Immunol. 10:2346. doi: 10.3389/fimmu.2019.02346

Yoshida, H., Okabe, Y., Kawane, K., Fukuyama, H., and Nagata, S. (2005). Lethal anemia caused by interferon-b produced in mouse embryos carrying undigested DNA. Nat. Immunol. 6, 49-56. doi: 10.1038/n i1146

Yuan, T., Zhang, L., Li, K., Fan, H., Fan, Y., Liang, J., et al. (2014). Collagen hydrogel as an immunomodulatory scaffold in cartilage tissue engineering. J. Biomed. Mater. Res. Part B Appl. Biomater. 102, 337-344. doi: 10.1002/jbm.b. 33011

Yue, Y., Yang, X., Feng, K., Wang, L., Hou, J., Mei, B., et al. (2017). M2b macrophages reduce early reperfusion injury after myocardial ischemia in mice: a predominant role of inhibiting apoptosis via A20. Int. J. Cardiol. 245, 228-235. doi: 10.1016/j.ijcard.2017.07.085

Zhang, C.-H., Jiang, Y.-L., Ning, L.-J., Li, Q., Fu, W.-L., Zhang, Y.-J., et al. (2018). Evaluation of decellularized bovine tendon sheets for achilles tendon defect reconstruction in a rabbit model. Am. J. Sports Med. 46, 2687-2699. doi: $10.1177 / 0363546518787515$

Zhang, J., Xie, B., Xi, Z., Zhao, L., Cen, L., and Yang, Y. (2020). A comparable study of polyglycolic acid's degradation on macrophages'activation. Mater. Sci. Eng. C Biomim. Supramol. Syst. 109:110574. doi: 10.1016/j.msec.2019.110574

Zhang, Q., Raoof, M., Chen, Y., Sumi, Y., Sursal, T., Junger, W., et al. (2010). Circulating mitochondrial DAMPs cause inflammatory responses to injury. Nature 464, 104-107.

Zhang, S., Chuah, S. J., Lai, R. C., Hui, J. H. P., Lim, S. K., and Toh, W. S. (2018). MSC exosomes mediate cartilage repair by enhancing proliferation, attenuating apoptosis and modulating immune reactivity. Biomaterials 156, 16-27. doi: 10.1016/j.biomaterials.2017.11.028

Zhao, P., Liu, S., Bai, Y., Lu, S., Peng, J., Zhang, L., et al. (2018). hWJECMDerived oriented scaffolds with autologous chondrocytes for rabbit cartilage defect repairing. Tissue Eng. Part A 24, 905-914. doi: 10.1089/ten.tea.2017.0223

Zheng, M. H., Chen, J., Kirilak, Y., Willers, C., Xu, J., and Wood, D. (2005). Porcine small intestine submucosa (SIS) is not an acellular collagenous matrix and contains porcine DNA: possible implications in human implantation. J. Biomed. Mater. Res. Part B Appl. Biomater. 73, 61-67. doi: 10.1002/jbm.b.30170

Zizzo, G., Hilliard, B. A., Monestier, M., and Cohen, P. L. (2012). Efficient clearance of early apoptotic cells by human macrophages requires M2c polarization and MerTK induction. J. Immunol. 189, 3508-3520. doi: 10.4049/jimmunol. 1200662

Conflict of Interest: The authors declare that the research was conducted in the absence of any commercial or financial relationships that could be construed as a potential conflict of interest.

Copyright (C) 2021 Wei, Liu, Chen, Tian, Zha, Yang, Jiang, Li, Sui, Chen and Guo. This is an open-access article distributed under the terms of the Creative Commons Attribution License (CC BY). The use, distribution or reproduction in other forums is permitted, provided the original author(s) and the copyright owner(s) are credited and that the original publication in this journal is cited, in accordance with accepted academic practice. No use, distribution or reproduction is permitted which does not comply with these terms. 